\title{
Interest on Reserves, Interbank Lending, and Monetary Policy
}

\author{
Stephen D. Williamson* \\ Federal Reserve Bank of St. Louis \\ P.O. Box 442, St. Louis, MO 63166-0442 \\ swilliamecon@gmail.com
}

February 1, 2016

\begin{abstract}
A two-sector general equilibrium banking model is constructed to study the functioning of a floor system of central bank intervention. Only retail banks can hold reserves, and these banks are also subject to a capital requirement, which creates "balance sheet costs" of holding reserves. An increase in the interest rate on reserves has very different qualitative effects from a reduction in the central bank's balance sheet. Increases in the central bank's balance sheet can have redistributive effects, and can reduce welfare. A reverse repo facility at the central bank puts a floor under the interbank interest rate, and is always welfare improving. However, an increase in reverse repos outstanding can increase the margin between the interbank interest rate and the interest rate on government debt.
\end{abstract}

\section{Introduction}

The purpose of this paper is to construct a two-sector banking model that can capture some idiosyncrasies of monetary policy implementation in the United States, and to use that model to explore the implications of monetary policy for the structure of market interest rates, the quantities of intermediated claims, and welfare. In particular, with a large quantity of reserves held in the banking system, the interbank interest rate is lower than the interest rate on reserves, changes in the size of the central bank's balance sheet have different effects than changes in the interest rate on reserves, and increasing the size of the central bank's balance sheet can reduce welfare. As well, expanding the reach

* This paper represents the views of the author, and not necessarily those of the Federal Reserve Bank of St. Louis, the Federal Reserve System, or its Board of Governors. Thanks to Jonas Crews for research assistance, and to participants at the Summer Workshop on Money, Banking, Payments and Finance at the St. Louis Fed, and at seminars at the St. Louis and Minneapolis Federal Reserve Banks, and Stanford University, for comments and suggestions. 
of interest-bearing central bank liabilities in the model, in a way that captures the role of the Fed's overnight reverse repurchase agreement (ON-RRP) facility, increases welfare.

Many central banks intervene in financial markets under "channel systems," according to which the central bank targets an overnight nominal interest rate, which is bounded by a rate of interest on central bank lending and a rate of interest on deposits at the central bank. Before the financial crisis, the Fed operated under a channel system, targeting the interest rate on federal funds, which was lower than the discount rate (the rate at which the Fed lends to commercial banks) and higher than the interest rate on reserves, which was zero. Institutional details and financial market structure are different across countries, but Canada, Switzerland, and the U.K, among others, could be characterized as channel system countries, at least before the financial crisis.

If there is a positive stock of central bank reserves outstanding in the financial system overnight, in excess of reserve requirements, then a necessary condition for a "floor system" is established. Under such a system of central bank intervention, arbitrage dictates that the interest rate on reserves determines the overnight rate, because private financial institutions have the option of either lending overnight to another private financial institution at the overnight rate, or lending to the central bank at the interest rate on reserves.

Should it make much economic difference whether the central bank intervenes in the context of a channel system or a floor system? In general, one might think not. Under a channel system the central bank intervenes via open market operations in the overnight market in order to peg the overnight nominal interest rate. Under a floor system, the central bank assures that there are sufficient reserves in the system, through open market operations, and then pegs the overnight rate by setting the interest rate on reserves. So, if the overnight nominal interest rate is the channel through which monetary policy affects inflation and real variables, it may seem that the choice between a channel system and a floor system is irrelevant.

Even if there were no economic difference between channel systems and floor systems, it has been argued that a floor system could represent an improvement for monetary policy implementation in the United States. Goodfriend (2002), writing before the Fed began paying interest on reserves in October 2008, argued that a floor system could make pegging the overnight interest rate in U.S. financial markets much easier. Before the financial crisis, the New York Fed would typically attempt to hit a given target for the fed funds rate by forecasting the demand for reserves on a given day, and then intervening to supply the quantity of reserves that would clear the fed funds market at the target interest rate. This procedure led to variability in the fed funds rate around the target, due to errors in forecasting reserve demand. However, according to Goodfriend, a floor system should allow the Fed to peg the fed funds rate simply by setting the nominal interest rate on reserves.

Goodfriend's ideas are certainly consistent with how floor systems have worked in other countries. For example, from April 2009 to May 2010, the Bank of Canada operated under a floor system in which it targeted overnight 
reserve balances at $\$ 3$ billion (Canadian) and set an interest rate on reserves of $0.25 \%$. Before and after this period, the Bank of Canada adhered to a channel system, in which the overnight target rate was bounded by the central bank's lending rate (overnight rate target plus $0.25 \%$ ), and the interest rate on reserves (overnight rate target minus 0.25\%). As can be seen in Figure 1, the Bank of Canada successfully pegged the overnight interest rate at $0.25 \%$ (the floor, i.e. the interest rate on reserves) over the period April 2009 to May 2010.

In the United States, the interest rate on reserves (IOER) was set at $0.25 \%$ from late 2008 until December 2015, when IOER was increased to $0.50 \%$. As well, the quantity of reserves in the financial system has been very large since the financial crisis, growing to almost $2 / 3$ of total Fed liabilities. Thus, the Fed has been operating under a floor system, but this system does not work as Goodfriend envisioned, or as the floor system worked in Canada. Figure 2 shows the path for the fed funds rate and the 3-month Treasury bill rate, postfinancial crisis. Clearly, fed funds have traded substantially below the interest rate on reserves, and short-term Treasury securities trade even lower.

What should we make of this? Some research has been done in an attempt to explain the deviation between IOER and the fed funds rate, for example Martin et al. (2013). The IOER/fed funds rate differential is typically ascribed to peculiarities associated with the payment of interest on reserves in the United States, and frictions related to arbitrage in overnight financial markets. When Congress amended the Federal Reserve Act to permit the payment of interest on reserves, the law prohibited the payment of interest on reserves to government sponsored enterprises (GSEs), including the Federal National Mortgage Association (Fannie Mae), the Federal Home Loan Mortgage Corporation (Freddie Mac), and the Federal Home Loan Banks (FHLBs). With the financial system flush with reserves, which removes typical idiosyncratic motives for trading on the fed funds market, the majority of fed funds lending is now done by FHLBs (see Afonso et al. 2013a).

But, even though the GSEs cannot receive interest on reserves, why do they not receive an interest rate very close to the interest rate on reserves when they lend on the fed funds market to a financial institution that can receive interest on reserves? The typical explanation provided (see for example Martin et al. 2013 ) is that there are costs - "balance sheet costs" - to commercial banks to expanding their reserves. For a bank, increasing assets implies an increase in its deposit insurance premium, and will also be costly in terms of binding capital requirements - required leverage ratios. This explanation is consistent with the observation (see Afonso et al. 2013b) that much of the borrowing in the fed funds market is currently done by the branches of foreign banks in the United States. These banks have no retail deposit business in the U.S. and therefore do not pay deposit insurance premia - they have low balance sheet costs.

For the Fed, the existence of a differential between the interest rate on reserves and its chosen target interest rate, the fed funds rate, presents a problem, in that the Fed may not be able to control the fed funds rate as desired, simply by setting IOER. Further, given the large quantity of reserves outstanding, and no plans to sell assets by the Fed in the future (see Board of Governors 2014), a 
floor system will be business as usual in the United States for many years (see Carpenter et al. 2013). Thus, this problem will be long-lasting. To deal with it, the Fed tested, and then implemented, a reverse repurchase agreement (ON RRP) facility, which in principle acts to bound the fed funds rate from below. ON RRPs are essentially reserves by another name. An expanded list of counterparties can now lend short-term (typically overnight) to the Fed, with the Fed posting securities in its portfolio as collateral, just as in standard private sector repo arrangements. These counterparties include money market mutual funds (MMMFs), which cannot hold reserves and do not bear balance sheet costs, as they have neither deposit insurance nor capital requirements. Thus, with an active ON RRP facility, MMMFs are likely to be the primary lenders. Following the increase in the Fed's target fed funds rate range from $0-0.25 \%$ to $0.25-0.50 \%$ on December 16,2015 , the ON-RRP facility seems to have been successful in putting a "sub-floor" under the fed funds rate.

Are these issues merely technical details? Are there important implications for monetary policy that we should be taking into account? A goal of this paper is to show that these things are indeed important. We construct a model in which two types of financial intermediaries emerge in equilibrium, retail banks and unconventional banks. Retail banks take deposits that are subject to withdrawal in currency, and these banks are regulated, in that they face a capital requirement - our version of balance sheet costs. Retail banks are also permitted to hold central bank reserves. Unconventional banks are unregulated, but they cannot hold reserves. These banks have different liabilities than do retail banks. We can interpret unconventional bank activities as issuing repos, secured with government debt, and issuing other intermediary liabilities, in order to finance an asset portfolio of private assets and government debt.

The model we construct is based on a Lagos-Wright (2005) structure, and is related to Williamson $(2012,2015 \mathrm{a}, 2015 \mathrm{~b})$ and Andolfatto and Williamson (2015). Other authors have studied channel systems (Berentsen and Monnet 2008), and have constructed more detailed models of trade on the fed funds market (Afonso and Lagos 2015 ). As well, Armenter and Lester (2015) examine a model of the fed funds market with an ON RRP facility and idiosyncratic trading motives in the overnight market. Those authors are interested in related issues, but approach the problem in a very different way. Bianchi and Bigio (2014) also study a model with interbank trading and monetary policy.

In the model, banks face a limited commitment problem. These institutions can run away from their liabilities, but their assets are effectively posted as collateral, so they do not default in equilibrium. As well, retail banks face capital requirements, which further restricts how much these financial intermediaries can borrow against their assets. In equilibrium, collateral constraints and capital constraints bind because there is a shortage of collateral in the economy. Essentially, suboptimal fiscal policy and a limited private capacity for production of safe private collateral creates a scarcity of collateral and inefficiency in exchange.

In this environment, in which there are reserves outstanding - a floor system - monetary policy has two dimensions. In general, both the interest rate on 
reserves and the size of the central bank's balance sheet will matter. However, the effect of changes in policy instruments depends on relative asset supplies, and whether the interbank market is active or inactive. In the model, there will be trade on the interbank market only as a means for unconventional banks to hold reserves indirectly - just as is currently the case in U.S. financial markets.

In some discussions of the effects of large-scale asset purchases (e.g. Bernanke 2012), quantitative easing is discussed as if increases in the size of the central bank's balance sheet are qualitatively the same as decreases in the overnight interest rate. Working in reverse, this view implies that a balance sheet reduction and an increase in the interest rate on reserves will have similar qualitative effects. In the model, a balance sheet reduction, given the nominal interest rate on reserves, typically acts to increase nominal interest rates (except for the interest rate on reserves, which is taken as given in the experiment), while an increase in the interest rate on reserves, given the size of the central bank's balance sheet, also increases other nominal interest rates, in particular the interbank interest rate and the interest rate on government debt. However, the similarities end there. The effects of changes in the two policy instruments have very different implications for quantities traded, welfare, and activity in the retail banking sector relative to the unconventional banking sector.

A key implication is that reducing the size of the central bank's balance sheet is unambiguously welfare-improving when the interbank market is active. This is because, when the interbank market is active, unconventional banks are indirectly holding reserves that exist on the balance sheets of retail banks, and this reserve-holding is costly. Thus, reducing the size of the central bank's balance sheet by swapping government debt for reserves effectively relaxes the capital constraints of retail banks, and the collateral constraints of unconventional banks.

When we add an ON-RRP facility, modeled as central bank interest-bearing liabilities that can be held by unconventional banks, this is unambiguously welfare-improving, because it reduces reserves, and therefore brings about a reduction in the balance sheet costs associated with central bank liabilities. As well, the ON RRP facility acts to put a floor under the interbank rate. Increasing the amount of ON RRP liabilities of the central bank always reduces the margin between the interest rate on reserves and the interbank rate. However, under some circumstances an increase in ON RRP liabilities acts to increase the margin between the interbank interest rate and the interest rate on government debt.

The paper is organized as follows. The second section contains a description of the model, while the third section deals with the problems solved by banks in the model. Then the next sections, four through nine, deal with the six types of equilibria that may exist in this model, depending on relative asset supplies. Section ten addresses issues related to an ON RRP facility, and the final section is a conclusion. 


\section{Model}

There exists a continuum of buyers with unit mass, each of whom has preferences

$$
E_{0} \sum_{t=0}^{\infty} \beta^{t}\left[-H_{t}+u\left(x_{t}\right)\right]
$$

where $H_{t}$ is labor supply in the $C M, x_{t}$ is consumption in the $D M$, with $u(\cdot)$ strictly increasing, twice continuously differentiable, and strictly concave. Assume $u^{\prime}(0)=\infty, u^{\prime}(\infty)=0$, and $-x \frac{u^{\prime \prime}(x)}{u^{\prime}(x)}<1$. There also exists a continuum of sellers with unit mass, each of whom has preferences

$$
E_{0} \sum_{t=0}^{\infty} \beta^{t}\left[-X_{t}+h_{t},\right]
$$

where $X_{t}$ denotes consumption in the $C M$, and $h_{t}$ denotes labor supply in the $D M$. Finally, there exists a continuum of bankers with unit mass, each of whom has preferences

$$
E_{0} \sum_{t=0}^{\infty} \beta^{t}\left[-X_{t}+H_{t} .\right]
$$

The consolidated government issues one-period nominal government bonds, each of which sells for $z_{t}^{b}$ units of money in the $C M$ and is a claim to one unit of money in the next $C M$; reserves, which sell at the price $z_{t}^{m}$ in the $C M$ and represent claims to money in the next $C M$; and currency, which sells at price $\phi_{t}$ in the $C M$. There also exists a fixed supply of private assets - a unit mass of Lucas trees - each of which pays off $y$ units of consumption goods in the $C M$ and trades in the $C M$ at the price $\psi_{t}$.

In the $C M$, all agents meet at the beginning of the period, debts are paid off, and the holders of private assets receive their payoffs. Then, production and consumption takes place, assets are traded, and economic agents write contracts with financial intermediaries. At the end of the period, each buyer can contact one banker.

In the $D M$, each buyer is matched with a seller, and the buyer makes a take-it-or-leave-it offer to the seller. Assume limited commitment (no one can be forced to work), and no memory, which implies that unsecured personal credit cannot be supported. There are three kinds of sellers, where type is determined by the types of collateral the seller is able to evaluate. A type $c$ seller accepts only currency, as this type of seller can only recognize the portable currency that the buyer carries with him or her. A type $b$ seller will accept currency or government bonds, as he or she is capable of evaluating only consolidated government liabilities. Finally, a type $a$ seller can evaluate all types of collateral - currency, government bonds, reserves, and private assets, as well as financial intermediary liabilities backed by these assets.

A fraction $\alpha$ of buyers are retail bank depositors (which will describe what they do in equilibrium), while the remaining fraction are unconventional bank 
depositors. For retail bank depositors, there is a probability $\rho$ that the buyer meets a type $c$ seller in the $D M$, in which case the buyer cannot trade unless he or she has brought currency with him or her. With probability $1-\rho$ the retail bank depositor meets a type $a$ seller in the $D M$. An unconventional bank depositor is matched with a different set of sellers. For such a buyer, there is a probability $\pi$ that he or she meets a type $b$ seller, and probability $1-\pi$ that he or she meets a type $a$ seller. At the beginning of the $C M$, buyers do not know what type of seller they will meet in the next $D M$ (though there are differences in the types of sellers that retail and unconventional bank depositors can meet, as specified above). However, each buyer learns this at the end of the $C M$.

We assume that, in $D M$ meetings, sellers do not have access to the histories of buyers. Thus, there is no recordkeeping, and sellers will not accept the IOUs of buyers in exchange in DM meetings. As well, there is no record of bankers' histories. There does, however, exist a collateral technology. Currency can be physically transferred between individuals, and other assets can be posted as collateral, and then seized by the lender if the debt is not settled. However, the ability of sellers to verify collateral is limited in the $D M$, as specified above.

\section{$2.1 \quad$ Government}

Each period, the consolidated government (the fiscal authority and central bank) has outstanding $C_{t}$ units of currency, $M_{t}$ units of reserves, and $B_{t}$ one-period government bonds, all in nominal terms. As well, the fiscal authority has access to lump-sum transfers (which can be negative) to buyers, with $\tau_{t}$ denoting the lump sum transfer per buyer, in units of the $C M$ good. The economy starts in period 0 with no consolidated government liabilities outstanding, so the period 0 consolidated government budget constraint is

$$
\phi_{0}\left(C_{0}+z_{0}^{m} M_{0}+z_{0}^{b} B_{0}\right)-\tau_{0}=0,
$$

and for periods $t=1,2,3, \ldots$, the constraint is

$$
\phi_{t}\left(C_{t}-C_{t-1}+z_{t}^{m} M_{t}-M_{t-1}+z_{t}^{b} B_{t}-B_{t-1}\right)-\tau_{t}=0 .
$$

We will assume that the central bank can only issue currency and reserves in exchange for the debt of the fiscal authority. Then, note that $B_{t}$ in (1) and (2) denotes bonds held in the private sector, outside the central bank.

\section{Banks' Problems}

In equilibrium, banks engage in two different types of intermediation activity. Retail banks and unconventional banks offer deposit contracts to retail bank depositors and unconventional bank depositors, respectively. In equilibrium, there is free entry into banking activity, so individual banks will be indifferent between

offering retail bank deposits and unconventional bank deposits, as either type of intermediation activity will yield an equilibrium discounted net payoff of zero. 
Retail banks are permitted by the government to hold reserves, while unconventional banks cannot. A retail bank offers a deposit contract $\left(k^{r}, c, d^{r}\right)$ to retail bank depositors, which requires the deposit of $k^{r}$ units of the consumption good with the bank at the beginning of the current $C M$, in return for an option either to withdraw $c$ in currency, in units of the $C M$ good, at the end of the current $C M$, or receive a tradeable claim to $d^{r}$ units of consumption in the next $C M$. We will confine attention to stationary equilibria in which prices are constant for all $t$, and $\mu$ denotes the gross inflation rate (which is endogenous). Given take-it-or-leave-it offers by retail bank depositors in the $D M$, the expected utility of a retail bank depositor from the deposit contract is

$$
U^{r}=-k^{r}+\rho u\left(\frac{\beta c}{\mu}\right)+(1-\rho) u\left(\beta d^{r}\right) .
$$

The retail bank takes in deposits, borrows on the interbank market, and invests in a portfolio of currency, government bonds, reserves, and private assets. The bank diversifies across a positive mass of depositors, exploiting the law of large numbers, and must earn a nonnegative expected return, i.e.

$k^{r}+z^{f} f^{r}-z^{b} b^{r}-z^{m} m-\psi q^{r}-\rho c-\beta(1-\rho) d^{r}+\frac{\beta\left(m+b^{r}-f^{r}\right)}{\mu}+\beta q^{r}(\psi+y) \geq 0$

In (4), $f^{r}$ denotes the real quantity of interbank borrowing by the bank, where each loan is a promise to pay one unit of money in the next $C M$, and $z^{f}$ denotes the price of a loan in terms of money in the current $C M$. In addition, in (4), $b^{r}, m$, and $q^{r}$ denote, respectively, the quantities of government bonds, reserves, and private assets acquired by the bank in the current $C M$ per depositor, with government bonds and reserves expressed in units of the $C M$ good. Bank liabilities are subject to limited commitment, but if a bank defaults the creditors can seize the bank's assets. Further, the government imposes a capital requirement on the retail bank, i.e. the maturity value of the bank's liabilities cannot exceed a fraction $1-\delta$ of the maturity value of the bank's assets, where $0<\delta<1$. This requires that the bank finance part of its portfolio of assets by working and producing goods in the $C M$ to acquire assets, so that the bank effectively supplies its own capital. Thus, the capital constraint for the bank is

$$
-(1-\rho) d^{r}-\frac{f^{r}(1-I)}{\mu}+\frac{\left(m+b^{r}-f^{r} I\right)(1-\delta)}{\mu}+q^{r}(\psi+y)(1-\delta) \geq 0 .
$$

Thus, if the capital constraint holds, then the bank does not have the incentive to abscond on its liabilities, as the constraint holds for $\delta=0$ (which gives the bank's incentive constraint from inequality (5)) if it holds for $\delta>0$. In equilibrium, a retail bank chooses a deposit contract $\left(k^{r}, c, d^{r}\right)$, and a portfolio $\left(f^{r}, b^{r}, m, q^{r}\right)$ to maximize $U^{r}$ subject to (4) and (5). If $f^{r}>0$ (the retail bank borrows on the interbank market), then $I=0$, whereas if $f^{r}<0$ (the retail bank lends on the interbank market), then $I=1$. The retail bank must also satisfy the nonnegativity constraints

$$
k^{r}, c, d^{r}, b^{r}, m, q^{r} \geq 0
$$


An unconventional bank has no capital requirement, it cannot hold reserves, and it offers deposit contracts to unconventional bank depositors. An unconventional bank depositor receives utility from a deposit contract

$$
U^{u}=-k^{u}+\pi u\left(\frac{\beta b^{\prime}}{\mu}\right)+(1-\pi) u\left(\beta d^{u}\right),
$$

where $k^{u}$ is the quantity of $C M$ goods deposited with the bank at the beginning of the $C M$, in exchange for an option to either withdraw $b^{\prime}$ in government bonds (in units of the current $C M$ good) at the end of the $C M$, or have access to tradeable claims to $d^{u}$ consumption goods in the next $C M$ (in units of time $t+1 C M$ goods). Then, in a manner similar to how we characterize an equilibrium deposit contract and portfolio allocation for a retail bank, an unconventional bank chooses a deposit contract $\left(k^{u}, b^{\prime}, d^{u}\right)$, and a portfolio $\left(b^{u}\right.$, $\left.f^{u}, q^{u}\right)$, where $b^{u}, f^{u}$, and $q^{u}$ denote, respectively, the quantity of government bonds acquired (in units of the $C M$ good), the quantity of interbank borrowing, and the quantity of private assets acquired, to maximize $U^{u}$ subject to the nonnegative present-value payoff constraint

$$
k^{u}+z^{f} f^{u}-z^{b} b^{u}-\psi q^{u}-\beta(1-\pi) d^{u}-\frac{\beta f^{u}}{\mu}+\frac{\beta\left(b^{u}-\pi b^{\prime}\right)}{\mu}+\beta q^{u}(\psi+y) \geq 0
$$

the incentive constraint

$$
-(1-\pi) d^{u}-\frac{f^{u}}{\mu}+\frac{b^{u}-\pi b^{\prime}}{\mu}+q^{u}(\psi+y) \geq 0,
$$

and nonnegativity constraints

$$
k^{u}, b^{\prime}, d^{u}, b^{u}, q^{u}, b^{u}-\pi b^{\prime} \geq 0 .
$$

\section{Equilibrium}

In solving the retail bank's problem, maximizing (3) subject to (4), 5), and (6), note first that (5) holds with equality. Then, in equilibrium, the following must hold:

$$
\begin{gathered}
\beta u^{\prime}\left(\beta d^{r}\right)-\beta-\lambda^{r}=0 \\
\frac{\beta}{\mu} u^{\prime}\left(\frac{\beta c}{\mu}\right)-1=0 \\
z^{f} \leq \frac{\beta}{\mu}+\frac{1}{\mu} \lambda^{r} \\
z^{f} \geq \frac{\beta}{\mu}+\frac{(1-\delta) \lambda^{r}}{\mu} \\
z^{b} \geq \frac{\beta}{\mu}+\frac{(1-\delta) \lambda^{r}}{\mu}
\end{gathered}
$$




$$
\begin{gathered}
z^{m}=\frac{\beta}{\mu}+\frac{(1-\delta) \lambda^{r}}{\mu} \\
-\psi+\beta(\psi+y)+\lambda^{r}(\psi+y)(1-\delta) \leq 0
\end{gathered}
$$

Equations (11) and (12) characterize the optimal deposit contract offered by the retail bank, where $\lambda^{r}$ denotes the multiplier on the capital constraint (5). In equilibrium, the stock of reserves must be held by retail banks, so (16) must hold, which states that the next discounted payoff for the retail bank from holding reserves must be zero. However, a retail bank may or may not be active on the interbank market (as a lender or borrower), and it may or may not hold government bonds or private assets. Thus, (13), (14), (15), and (17) are weak inequalities, i.e. the net payoff to borrowing or lending on the interbank market, to holding government debt, and to holding private assets, must not be strictly positive in equilibrium.

Similarly, for unconventional banks, from the problem of maximizing (7) subject to (8)-(10), the following must hold in equilibrium:

$$
\begin{gathered}
\beta u^{\prime}\left(\beta d^{u}\right)-\beta-\lambda^{u}=0 \\
\frac{\beta}{\mu} u^{\prime}\left(\frac{\beta b^{\prime}}{\mu}\right)-z^{b}=0 \\
u^{\prime}\left(\frac{\beta b^{\prime}}{\mu}\right)=u^{\prime}\left(\beta d^{u}\right), \text { if } b^{u}-\pi b^{\prime}>0, \\
u^{\prime}\left(\frac{\beta b^{\prime}}{\mu}\right) \geq u^{\prime}\left(\beta d^{u}\right), \text { if } b^{u}-\pi b^{\prime}=0, \\
z^{f}=\frac{\beta}{\mu}+\frac{1}{\mu} \lambda^{u} \\
-\psi+\beta(\psi+y)+\lambda^{u}(\psi+y)=0
\end{gathered}
$$

Equations (18)-(21) determine the optimal deposit contract for an unconventional bank. Equation (22) states that the unconventional bank must be indifferent in equilibrium between borrowing and lending on the interbank market, while equation (23) must hold as the unconventional bank must hold private assets in any equilibrium.

In a stationary equilibrium, define real consolidated government asset quantities as $\bar{c} \equiv \phi_{t} C_{t}, \bar{m} \equiv \phi_{t} M_{t}, \bar{b} \equiv \phi_{t} B_{t}$. Then, from (1) and (2), we can express the consolidated government's budget constraints in a stationary equilibrium as

$$
\begin{gathered}
\bar{c}+z^{m} \bar{m}+z^{b} \bar{b}=\tau_{0}, \\
\left(1-\frac{1}{\mu}\right) \bar{c}+\left(z^{m}-\frac{1}{\mu}\right) \bar{m}+\left(z^{b}-\frac{1}{\mu}\right) \bar{b}=\tau,
\end{gathered}
$$

where $\tau_{0}$ is the lump sum transfer to each buyer in the $C M$ in period 0 , and $\tau$ is the lump sum transfer to each buyer in the $C M$ of each succeeding period. 
We will assume a particular fiscal policy rule, which is that the government sets taxes so that

$$
z^{m} \bar{m}+z^{b} \bar{b}+\bar{c}=V,
$$

where $V>0$ is constant, i.e. the fiscal authority pegs the real value of the outstanding consolidated government debt to a constant forever. This implies that $\tau_{0}=V$ is exogenous, but $\tau$ is endogenous, and from (25) and (26) it is determined by

$$
V\left(1-\frac{1}{\mu}\right)+\frac{\bar{m}}{\mu}\left(z^{m}-1\right)+\frac{\bar{b}}{\mu}\left(z^{b}-1\right)=\tau
$$

Definition 1 A stationary equilibrium with binding collateral constraints consists of quantities $\left(\bar{m}, \bar{b}, \bar{c}, d^{r}, d^{u}, c, m, f^{r}, b^{r}, q^{r}, b^{u}, b^{\prime}, q^{u}, f^{u}\right)$, prices $\left(z^{f}, \psi\right)$, multipliers $\left(\lambda^{r}, \lambda^{u}\right)$, and gross inflation rate $\mu$, satisfying (5) and (9) with equality, (11)-(23), (26), and market clearing,

$$
\begin{gathered}
\alpha b^{r}+(1-\alpha) b^{u}=\bar{b}, \text { [government bond market clears] } \\
\alpha \rho c=\bar{c}, \text { [market in currency clears] } \\
\alpha q^{r}+(1-\alpha) q^{u}=1, \text { [market in private assets clears] } \\
\alpha m=\bar{m}, \text { [market in reserves clears] } \\
\alpha f^{r}+(1-\alpha) f^{u}=0, \text { [interbank market clears] }
\end{gathered}
$$

given fiscal policy $V$ and monetary policy $\left(z^{m}, V-z^{b} \bar{b}\right)$.

The equilibria we will be focusing on are ones in which the capital and collateral constraints of banks bind, so the multipliers $\lambda^{r}$ and $\lambda^{u}$ associated respectively with the constraints (5) and (9) are strictly positive. For such equilibria to exist requires that $V$ be sufficiently small. Thus, the value of the consolidated government debt needs to be small enough so that the assets that are needed to support exchange are in short supply. As well, $y$ needs to be sufficiently small, so that the value of private collateral is in short supply. We will investigate this further when we construct equilibria.

There are different ways we could specify monetary policy here, but in general it will have two dimensions. It is convenient in this model, and helps in drawing conclusions with regard to current central banking policy in the United States, to specify policy in terms of the price of reserves, $z^{m}$, which determines the nominal interest rate on reserves, and $V-z^{b} \bar{b}$, which is the real value of the central bank's liabilities, i.e. the size of the central bank's balance sheet. This leaves the asset quantities $\bar{m}, \bar{b}$, and $\bar{c}$ endogenous. Thus, the central bank sets the nominal interest rate on reserves, determines the size of its balance sheet, given fiscal policy, and then private economic agents determine the nominal interest rate on government debt and how outside money is split between currency and reserves.

In equilibrium, exchange on the interbank market will be between retail banks and unconventional banks. There is thus an element of interbank market 
behavior in the United States that we do not capture here, and which has been studied by Armenter and Lester (2015) and Afonso and Lagos (2015), for example. That is, most exchange on the fed funds market before the financial crisis was for idiosyncratic reasons, rather than in an attempt to arbitrage away differences in rates of return, as will be the case in this model. For our purposes, trade due to idiosyncratic shocks on the interbank market is not of interest, so we want to leave that out, and focus on how financial institutions attempt to arbitrage interest on reserves, as in the post-financial crisis period.

As we will see, under some conditions, trade on the interbank market will be zero, but when that is not the case unconventional banks will be lenders and conventional banks will be borrowers. Basically, trade on the interbank market will be a means for unconventional banks to hold reserves indirectly. In what follows, we will examine the six different types of equilibria that can arise. In the first four the interbank market is inactive, and in the latter two it will be active.

It is fruitful to interpret exchange between unconventional bank depositors and type $b$ sellers in the $D M$, as repo market activity. Under this interpretation, if an unconventional depositor learns at the end of the $C M$ that he or she will meet a type $b$ buyer in the subsequent $C M$, the unconventional bank then sets aside a specified quantity of government bonds as collateral backing the bank's debt to the depositor. The depositor can then trade this debt with the seller he or she meets in the $D M$, in exchange for goods. This looks like an arrangement whereby the depositor has engaged in a repo contract with the unconventional bank, with government debt posted as collateral, and then that collateral is rehypothecated when the depositor meets the seller in the $D M$. When debts are settled in the next $C M$, the depositor repurchases the collateral from the seller, then the bank repurchases the collateral from the depositor.

\section{Baseline Case: Inactive Interbank Market; Re- tail and Unconventional Banks Hold Govern- ment Bonds and Private Assets}

In all the cases we examine, assets will be scarce in the sense that there are insufficient quantities of government liabilities, central bank liabilities, and private assets to finance efficient exchange. The different cases will differ, however, depending on the relative scarcity of different assets - when a particular asset is relatively scarce, this can induce market segmentation. In the baseline case, financial markets will not be segmented, as government bonds and private assets are sufficiently plentiful relative to other assets. In particular, in this equilibrium all financial intermediaries hold government bonds and private assets on their balance sheets, and not all government bonds are used in exchange by unconventional bank depositors meeting type $b$ sellers in the $D M$. Throughout, we will study equilibria away from the zero lower bound on nominal interest rates, that is $z^{i}<1$ for $i=m, b, f$. In this equilibrium, the fact that retail banks and 
unconventional banks participate in the same asset markets will imply that the interbank market is inactive, as we will show.

It proves convenient, as in Williamson (2015a, 2015b), to solve for a stationary equilibrium in terms of the quantities of goods traded in the $D M$. Let $x^{r c}$ and $x^{r a}$ denote the consumption of retail bank depositors in $D M$ trades where, respectively, the buyer meets a type $c$ seller and when the buyer meets a type $a$ seller. For unconventional bank depositors, the quantities $x^{u b}$ and $x^{u a}$ denote, respectively, consumption by the buyer when he or she meets a type $b$ seller and when he or she meets a type $a$ seller.

First, from (11) and (18), we can write the multipliers associated with banks' collateral constraints as

$$
\lambda^{i}=\beta\left[u^{\prime}\left(x^{i a}\right)-1\right] \text {, for } i=r, u \text {. }
$$

Therefore, binding collateral constraints are associated with inefficiency in $D M$ transactions involving bank deposits, as surplus-maximizing transactions imply $u^{\prime}\left(x^{i a}\right)=1$, and there is inefficiency if and only if $u^{\prime}\left(x^{i a}\right)>1$.

Then, because government bonds are held to back the deposits of retail banks and unconventional banks in this equilibrium, i.e. $b^{u}>\pi b^{\prime}$, then, from (33), (15), (19), and (20), we get

$$
z^{b}=\frac{\beta}{\mu}\left[(1-\delta) u^{\prime}\left(x^{r a}\right)+\delta\right]=\frac{\beta}{\mu} u^{\prime}\left(x^{u a}\right)=\frac{\beta}{\mu} u^{\prime}\left(x^{u b}\right) .
$$

Note from (34) that the capital requirement, i.e. $\delta>0$, implies that $x^{r a}<$ $x^{u a}$. Thus, in this equilibrium balance sheet costs in the retail banking sector constrain consumption by depositors in that sector.

Equation (12) gives

$$
\mu=\beta u^{\prime}\left(x^{r c}\right)
$$

so the gross inflation rate depends only on the inefficiency in the market in which currency is exchanged for goods in the $D M$.

From (23) and (33), we can solve for the price of private assets,

$$
\psi=\frac{\beta u^{\prime}\left(x^{u a}\right) y}{1-\beta u^{\prime}\left(x^{u a}\right)}
$$

Then, from (5), (9), (26), (28)-(31), and (34)-(36), we obtain

$$
\frac{\alpha(1-\rho) x^{r a}\left[(1-\delta) u^{\prime}\left(x^{r a}\right)+\delta\right]}{1-\delta}+(1-\alpha) x^{u a} u^{\prime}\left(x^{u a}\right)+\alpha \rho x^{r c} u^{\prime}\left(x^{r c}\right)=V+\frac{\beta u^{\prime}\left(x^{u a}\right) y}{1-\beta u^{\prime}\left(x^{u a}\right)}
$$

Further, from (34) and (35), we have

$$
\begin{gathered}
z^{b}=z^{m}=z^{f}=\frac{u^{\prime}\left(x^{u a}\right)}{u^{\prime}\left(x^{r c}\right)} \\
x^{u b}=x^{u a}
\end{gathered}
$$




$$
(1-\delta) u^{\prime}\left(x^{r a}\right)+\delta=u^{\prime}\left(x^{u a}\right) .
$$

Then, (37)-(40) solve for $x^{r c}, x^{r a}, x^{u b}$, and $x^{u a}$, given fiscal policy $V$ and monetary policy $z^{m}$. To solve for the remaining interest rates, $z^{m}=z^{f}=z^{b}$, so the interest rate on reserves, the interbank market interest rate, and the interest rate on government bonds are identical in the baseline case. As we will show, the size of the central bank's balance sheet will be irrelevant in this case. So far, it is clear that we can solve for an equilibrium given only the interest rate on reserves.

The gross real rates of return on Lucas trees, government debt, reserves, and interbank loans are all equal to

$$
r=\frac{1}{\beta u^{\prime}\left(x^{u a}\right)}=\frac{1}{\beta u^{\prime}\left(x^{u b}\right)}=\frac{1}{\beta\left[(1-\delta) u^{\prime}\left(x^{r a}\right)+\delta\right]}
$$

In equation (37), the expression $x^{r a}\left[(1-\delta) u^{\prime}\left(x^{r a}\right)+\delta\right]$ is strictly increasing in $x^{r a}$, because $-x \frac{u^{\prime \prime}(x)}{u^{\prime}(x)}<1$. As well because, in (40), the left-hand side of the equation is strictly decreasing in $x^{r a}$ and the right-hand side is strictly decreasing in $x^{u a}$, we can use (40) to write equation (37) in the form

$$
F\left(x^{r c}, x^{u a}\right)=V
$$

where the function $F(\cdot, \cdot)$ is strictly increasing in both arguments.

Let $x^{*}$ denote the solution to $u^{\prime}\left(x^{*}\right)=1$. That is, $x^{*}$ is the surplus-maximizing quantity of consumption in a $D M$ exchange between a buyer and seller. Then, if

$$
V+\frac{\beta y}{1-\beta}<\frac{[1-\alpha \rho-\delta(1-\alpha)] x^{*}}{1-\delta},
$$

the capital constraint (5) and the incentive constraint (9) for retail banks and unconventional banks, respectively, will bind in this equilibrium for any $z^{m} \in$ $(0,1)$. If exchange is efficient in trades in the $D M$ involving type $a$ sellers then, from (33), incentive constraints will not bind for retail banks and unconventional banks. If that is the case, then, from (37), inequality (43) states that the value of assets in equilibrium - the value of consolidated government liabilities plus the value of private assets, on the left-hand side of inequality (43) - is insufficient to support this level of exchange.

To solve for an equilibrium, we need to first find $\left(x^{r c}, x^{u a}\right)$ by solving (42) and (38) given $z^{m}$ and $V$. The properties of $F(\cdot, \cdot)$ imply that the solution is unique, as depicted in Figure 3. The locus $I C$ in the figure is determined by (42), which was derived from the banks' incentive constraints, along with equilibrium conditions, and $M P$ is the locus determined by (38), the position of which is given by $z^{m}$. That is, the $M P$ locus shifts with monetary policy.

From (34), (33), (35), and (13), the net payoff for a retail bank to borrowing one unit of $C M$ goods on the interbank market at equilibrium prices is

$$
z^{f}-\frac{\beta}{\mu}-\frac{1}{\mu} \lambda^{s}=\frac{\delta}{u^{\prime}\left(x^{r c}\right)}\left[1-u^{\prime}\left(x^{r a}\right)\right]<0 .
$$


Similarly, the equilibrium net payoff for a retail bank from lending on the interbank market, given (14), is

$$
-z^{f}+\frac{\beta}{\mu}+\frac{(1-\delta) \lambda^{s}}{\mu}=0 .
$$

Thus, retail banks strictly prefer not to borrow on the interbank market in equilibrium, but they are indifferent concerning how much they lend on the interbank market. As well, given how the equilibrium is constructed, unconventional banks are indifferent between borrowing and lending on the interbank market. Therefore, if a baseline equilibrium exists, there is an equilibrium in which there is no interbank lending. There are also equilibria in which retail banks lend to unconventional banks on the interbank market, but all equilibria have the same allocation of resources and, in particular, support the same consumption quantities for buyers in $D M$ exchange. In equilibria in which there is trade on the interbank market, unconventional banks hold bonds and private assets, and borrow from retail banks to purchase these assets, so that retail banks are effectively holding those assets indirectly, and it makes no economic difference that they do so. Thus, in any baseline equilibrium, the interbank market is either inactive or irrelevant.

Finally, we need to understand the complete mechanics of monetary policy in this equilibrium. As all short-term interest rates - the interest rates on reserves, the interbank market interest rate, and the interest rate on government debt are equated in equilibrium, the central bank determines all short-term interest rates by setting the price of reserves $z^{m}$, thus setting the nominal interest rate on reserves. Also, recall that the central bank controls the size of its balance sheet, which we will denote by $k=V-z^{b} \bar{b}$, where $k$ is exogenous. But currency and reserves are then determined endogenously, working backward from the solution to (37)-(40). Then, in equilibrium there must be just enough currency outstanding to finance purchases by retail bank depositors who meet type $c$ sellers in the $D M$, so using (35),

$$
\bar{c}=\alpha \rho x^{r c} u^{\prime}\left(x^{r c}\right) .
$$

Then, from the consolidated government's budget constraint, (26), and (44), the quantity of reserves is

$$
z^{m} \bar{m}=k-\alpha \rho x^{r c} u^{\prime}\left(x^{r c}\right)
$$

Finally, the stock of government debt outstanding needs to be large enough to support exchange by unconventional bank depositors who meet type $b$ sellers in the $D M$, or, using (34)

$$
V-k \geq(1-\alpha) \pi x^{u a} u^{\prime}\left(x^{u a}\right) .
$$

As well, there needs to be enough government debt and private assets, such that all transactions by unconventional bank depositors can be supported, or

$$
V-k \geq(1-\alpha) x^{u a} u^{\prime}\left(x^{u a}\right)-\frac{\beta y u^{\prime}\left(x^{u a}\right)}{1-\beta u^{\prime}\left(x^{u a}\right)} .
$$


In this equilibrium $k$, the size of the central bank's balance sheet, is irrelevant, but for the equilibrium to exist, (45)-(47) give the following necessary conditions for existence of the equilibrium, which we can rewrite as:

$$
\begin{aligned}
\alpha \rho x^{r c} u^{\prime}\left(x^{r c}\right) \leq & k \leq V-(1-\alpha) \pi x^{u a} u^{\prime}\left(x^{u a}\right) \\
& +\min \left[0,-(1-\alpha)(1-\pi) x^{u a} u^{\prime}\left(x^{u a}\right)+\frac{\beta y u^{\prime}\left(x^{u a}\right)}{1-\beta u^{\prime}\left(x^{u a}\right)}\right] .
\end{aligned}
$$

Thus, the central bank's balance sheet cannot be too small nor too large, given the setting for the nominal interest rate on reserves, which determines $\left(x^{r c}, x^{r a}, x^{u b}, x^{u a}\right)$.

\subsection{Effects of Monetary Policy}

The only monetary policy instrument that matters in this equilibrium is the interest rate on reserves. At the margin, changes in the size of the Fed's balance sheet are irrelevant, as swapping reserves for government debt implies only a reshuffling of bank asset portfolios, with no effect on prices or consumption. Effectively, this is a liquidity trap, but $z^{m}<1$ in equilibrium, so this is a liquidity trap away from the zero lower bound.

What then are the effects of a change in $z^{m}$ ? As noted previously, $z^{m}=z^{b}=$ $z^{f}$, so the interest rate on reserves determines the interest rate on government debt and the interest rate on interbank loans. From our previous analysis, we can determine $\left(x^{r c}, x^{u a}\right)$ from $(38)$ and $(42)$, where the function $F(\cdot, \cdot)$ is strictly increasing in both arguments. Therefore, suppose initially $z^{m}=z_{1}$ and then $z^{m}$ decreases to $z_{2}<z_{1}$, so that the nominal interest rates on reserves, government debt, and interbank loans increase. In Figure 4, the curve $I C$ denotes the locus determined by equation (42), and the increase in the nominal interest rate on reserves shifts the curve $M P_{1}$ up to $M P_{2}$. As a result, $x^{r c}$ falls and $x^{u a}$ rises, and from (39) and (40), $x^{u b}$ and $x^{r a}$ rise as well. From (35), the inflation rate rises. Further, from (41), the real interest rate has risen, as banks' collateral constraints have been relaxed - because $x^{r c}$ has fallen. From (44), currency outstanding has fallen, so the increase in the interest rate on reserves has resulted in substitution from currency to reserves (given that $k$, the size of the central bank's balance sheet, is fixed). We can think of the adjustment happening through deposits of currency in retail banks' reserve accounts with the central bank, with no change in the size of the central bank's balance sheet.

\section{Scarce Government Bonds, Plentiful Private Collateral}

In this case, government bonds are in short enough supply that they are used only by unconventional bank depositors when they meet a type $b$ seller - bonds are not held to back the tradeable claims of either type of bank. But the interbank market is inactive (or active and redundant) in this case, as private 
assets are not traded in a segmented market, just as in the previous section. That is, private assets are held as assets by retail banks and non-conventional banks, so these two types of institutions face the same rates of return on assets backing deposit liabilities, and so have no incentive to trade on the interbank market.

In (19) and (21), $\pi b^{\prime}=b^{u}$, so given (33),

$$
z^{b}=\frac{\beta}{\mu} u^{\prime}\left(x^{u b}\right)
$$

From (16), (17), (23), and (33), we have

$$
z^{m}=z^{f}=\frac{\beta}{\mu}\left[(1-\delta) u^{\prime}\left(x^{r a}\right)+\delta\right]=\frac{\beta}{\mu} u^{\prime}\left(x^{u a}\right),
$$

and (36). As well, (35) holds. Note that, from (21),

$$
z^{b} \geq z^{f}=z^{m}
$$

in this equilibrium. That is, the nominal interest rate is lower on government bonds than on interbank lending and reserves, reflecting a higher liquidity premium on government bonds than on other assets. The gross real rates of return on private assets and reserves are given by

$$
r^{m}=\frac{1}{\beta u^{\prime}\left(x^{u a}\right)}=\frac{1}{\beta\left[(1-\delta) u^{\prime}\left(x^{r a}\right)+\delta\right]},
$$

while the gross real rate of return on government debt is

$$
r^{b}=\frac{1}{\beta u^{\prime}\left(x^{u b}\right)}
$$

Therefore, because $x^{u b} \leq x^{u a}$ in this equilibrium, we have $r^{b} \leq r^{m}$, as government debt bears a higher liquidity premium than do private assets and reserves.

Then, from (5), (9), (26), (28), (30), and (31), we obtain

$$
\begin{aligned}
& \frac{\alpha(1-\rho) x^{r a}\left[(1-\delta) u^{\prime}\left(x^{r a}\right)+\delta\right]}{1-\delta}+(1-\alpha)(1-\pi) x^{u a} u^{\prime}\left(x^{u a}\right) \\
& +\alpha \rho x_{1}^{r} u^{\prime}\left(x_{1}^{r}\right)+(1-\alpha) \pi x^{u b} u^{\prime}\left(x^{u b}\right) \\
= & V+\frac{\beta u^{\prime}\left(x^{u a}\right) y}{1-\beta u^{\prime}\left(x^{u a}\right)}
\end{aligned}
$$

Also, from (49), (50) and (35), we have

$$
\begin{aligned}
& z^{b}=\frac{u^{\prime}\left(x^{u b}\right)}{u^{\prime}\left(x^{r c}\right)}, \\
& z^{m}=\frac{u^{\prime}\left(x^{u a}\right)}{u^{\prime}\left(x^{r c}\right)} .
\end{aligned}
$$




$$
(1-\delta) u^{\prime}\left(x^{r a}\right)+\delta=u^{\prime}\left(x^{u a}\right)
$$

Just as in the case considered in the last section, the size of the central bank's balance sheet $k$ is exogenous. Because government bonds are used only to finance $D M$ transactions by unconventional bank depositors meeting type $b$ sellers, using (49) we get

$$
V-k=(1-\alpha) \pi x^{u b} u^{\prime}\left(x^{u b}\right)
$$

Next, to solve the model in terms of monetary policy instruments - the nominal interest rate on reserves and the size of the central bank's balance sheet, given (57), we can rewrite (53) as

$$
\begin{aligned}
& \frac{\alpha(1-\rho) x^{r a}\left[(1-\delta) u^{\prime}\left(x^{r a}\right)+\delta\right]}{1-\delta}+(1-\alpha)(1-\pi) x^{u a} u^{\prime}\left(x^{u a}\right)+\alpha \rho x^{r c} u^{\prime}( \\
= & k+\frac{\beta u^{\prime}\left(x^{u a}\right) y}{1-\beta u^{\prime}\left(x^{u a}\right)}
\end{aligned}
$$

Then, given $z^{m}$ and $k$, the price of reserves and the size of the central bank's balance sheet, (58), (57), and (56) imply that there are two equations that solve for $\left(x^{r c}, x^{u a}\right)$ in equilibrium:

$$
G\left(x^{r c}, x^{u a}\right)=k
$$

and $(55)$, where $G(\cdot, \cdot)$ is strictly increasing in both arguments. We can draw a figure similar to Figure 3, except with the curve $I C$ determined by (59) and the curve $M P$ describing the relationship given by (55), to depict the equilibrium solution. Then, given the solution for $\left(x^{r c}, x^{u a}\right)$, (56) solves for $x^{r a}$. Finally, (57) solves for $x^{u b}$ given $V$ and $k$.

As in the previous section, the quantity of currency outstanding, $\bar{c}$, is determined by (44). Then, similar to (48), we can put bounds on $k$,

$$
\alpha \rho x^{r c} u^{\prime}\left(x^{r c}\right) \leq k \leq \alpha \rho x^{r c} u^{\prime}\left(x^{r c}\right)+\frac{\alpha(1-\rho) x^{r a}\left[(1-\delta) u^{\prime}\left(x^{r a}\right)+\delta\right]}{1-\delta},
$$

that is total central bank liabilities must be larger than the quantity of currency required to support an equilibrium, and smaller than currency plus the quantity of assets required to support exchange by retail bank depositors who meet type $a$ sellers in the $D M$.

Just as in our analysis of the baseline equilibrium, retail banks strictly prefer not to borrow on the interbank market in equilibrium, but are indifferent as to how much they lend. As well, unconventional banks are indifferent between borrowing and lending. Thus, just as in the baseline equilibrium, there is an equilibrium in which the interbank market is inactive, but there exist other equilibria in which retail banks lend to unconventional banks, though this lending and borrowing is irrelevant for any quantities and prices of consequence. 


\subsection{Effects of Monetary Policy}

Determining the quantitative effects of monetary policy is now straightforward in this equilibrium. First, consider the effects of an increase in the interest rate on reserves, holding $k$, balance sheet size, fixed. Just as in Figure 4 , the $M P$ curve shifts up from $M P_{1}$ to $M P_{2}$, so $x^{r c}$ falls and $x^{u a}$ increases. Therefore, from (56), $x^{r a}$ also increases. From (57), $x^{u b}$ does not change, and, from (54), $z^{b}$ falls, so the nominal interest rate on government debt rises.

With the central bank's balance sheet fixed in size, an increase in the nominal interest rate on reserves results in substitution from currency to reserves. From (44), the quantity of currency falls in real terms, implying an increase in the value of reserves outstanding. Given the smaller stock of currency, transactions financed with currency fall, and the larger stock of reserves finances more transactions using bank deposits - retail and unconventional. In spite of

the fact that reserves are not held by unconventional banks, the larger stock of reserves frees up private assets, which are then held by unconventional banks. The nominal interest rate on government debt rises due to an inflation premium effect. To induce retail bank depositors to use a smaller stock of currency in real terms, the inflation rate must rise.

The difference between the gross nominal interest rates on reserves and government debt is given, from (54) and (55), by

$$
\frac{1}{z^{m}}-\frac{1}{z^{b}}=u^{\prime}\left(x^{r c}\right)\left[\frac{1}{u^{\prime}\left(x^{u a}\right)}-\frac{1}{u^{\prime}\left(x^{u b}\right)}\right] .
$$

As $x^{r c}$ decreases, $x^{u a}$ increases, and $x^{u b}$ remains unchanged when $z^{m}$ falls, the margin between the nominal interest rate on reserves and the nominal interest rate on government debt increases. This occurs because the increase in inflation increases the inflation premium on both assets, and the margin between the real rates of interest on reserves and government debt increases.

Second, holding constant the interest rate on reserves, so $z^{m}$ is fixed, consider a reduction in the size of the central bank's balance sheet $-k$ decreases. This implies that, in Figure 5, the $I C$ curve shifts to the left from $I C_{1}$ to $I C_{2}$. Then, there is a reduction in $x^{r c}$ and in $x^{u a}$ as well as a decrease in $x^{r a}$, from (56). But, given (??), $x^{u b}$ increases. From (54), $z^{b}$ decreases, and given (51) and (52), the real rates of return on reserves and private assets fall, while the real rate of return on government debt rises.

An important point to emphasize here is the difference between the effects of monetary "tightening" by way of an increase in the nominal interest rate on reserves and a reduction in the size of the central bank's balance sheet. While an increase in the interest rate on reserves induces a substitution between two central bank liabilities, currency and reserves, a balance sheet reduction acts to reduce total central bank liabilities and increase the quantity of government debt outstanding. As a result, transactions by retail bank depositors in the $D M$, using both currency and deposits, will decrease, and these retail bank depositors will be unambiguously worse off. But depositors at unconventional banks who ultimately use government debt in transactions will consume more, 
as government debt is more plentiful. The nominal interest rate on government debt rises for two reasons. First, the real rate of return on government debt is higher as the supply of government debt is higher and the liquidity premium on government debt is lower. Second, inflation has risen, so there is a higher inflation premium on government debt. Finally, the real return on reserves and private assets falls because the collateral constraints of retail banks and unconventional banks are tighter.

Note that, if $k$ increases, then the margin between the nominal interest rate on reserves and the nominal interest rate on government debt will increase. This is due to the fact that increasing the central bank's balance sheet reduces the inflation rate, reducing the inflation premium on government debt, and makes government debt more scarce, increasing the liquidity premium on this asset and reducing its real rate of return.

\section{Scarce Government Bonds and Private Col- lateral; Inactive Interbank Market}

In this equilibrium, government bonds and private assets are collectively in short supply relative to reserves, to the point where these assets are not held by retail banks. However, the quantity of reserves is low enough that there is no activity on the interbank market. As well, there are enough government bonds relative to private assets that bonds and private assets both back unconventional bank deposits. That is, not all government bonds are used in exchange by unconventional bank depositors who meet type $b$ sellers in the $D M$.

While the resulting equilibrium will look extreme, as retail banks hold a portfolio consisting only of reserves with the central bank, so that they are effectively "narrow" banks, it can be argued that this captures the essentials of what we are after. We could complicate the model by including asset specialization by retail banks and unconventional banks - the two types of banks could have a comparative advantage in particular types of lending. This would not add anything, as all that is essential for this type of equilibrium (and the ones in the next sections) is that the two types of banks not have any assets in common in their portfolios.

In this equilibrium, (53) holds, but the configuration of rates of return on assets is different, and we need to characterize an equilibrium somewhat differently. Given that unconventional banks hold government bonds to back deposits, and, from (22) and (33), we have

$$
z^{b}=z^{f}=\frac{u^{\prime}\left(x^{u a}\right)}{u^{\prime}\left(x^{r c}\right)} .
$$

and (39). As well, for retail banks to be willing to hold reserves,

$$
z^{m}=\frac{(1-\delta) u^{\prime}\left(x^{r a}\right)+\delta}{u^{\prime}\left(x_{1}^{r}\right)} .
$$


But retail banks have to be willing not to hold government bonds in equilibrium, which requires $z^{m} \leq z^{b}$ or

$$
(1-\delta) u^{\prime}\left(x^{r a}\right)+\delta \leq u^{\prime}\left(x^{u a}\right) .
$$

Inequality (63) also implies that a retail bank does not wish to lend on the interbank market. As well, retail banks cannot have an incentive to borrow on the interbank market or, from (13),

$$
u^{\prime}\left(x^{r a}\right) \geq u^{\prime}\left(x^{u a}\right) .
$$

Further, the gross real rate of return on reserves is

$$
r^{m}=\frac{1}{\beta\left[(1-\delta) u^{\prime}\left(x^{r a}\right)+\delta\right]},
$$

while the gross real rate of return on government bonds and private assets is

$$
r^{b}=\frac{1}{\beta u^{\prime}\left(x^{u a}\right)},
$$

so, from (63), we have $r^{m} \geq r^{b}$. Arbitrage is imperfect - rates of return are not equalized on reserves, government debt, and private assets. This occurs in this equilibrium because only retail banks can hold reserves, and because retail banks face a capital requirement, which makes holding reserves costly.

Given $k$, the size of the central bank's balance sheet, from (??) and (53),

$$
=\frac{\alpha(1-\rho) x^{r a}\left[(1-\delta) u^{\prime}\left(x^{r a}\right)+\delta\right]}{1-\delta}+\alpha \rho x^{r c} u^{\prime}\left(x^{r c}\right)
$$

Then, given $k$ and $z^{m}$, equations (67) and (62) solve for $\left(x^{r c}, x^{r a}\right)$. Because government debt and private assets finance the consumption of unconventional bank depositors in the $D M$,

$$
V-k=(1-\alpha) x^{u a} u^{\prime}\left(x^{u a}\right)-\frac{\beta u^{\prime}\left(x^{u a}\right) y}{1-\beta u^{\prime}\left(x^{u a}\right)},
$$

which solves for $x^{u a}=x^{u b}$ given $k$.

In equilibrium, there must also be sufficient government debt to finance the consumption of unconventional bank depositors who meet type $b$ sellers in the $D M$, so from (68),

$$
(1-\alpha)(1-\pi) x^{u a} u^{\prime}\left(x^{u a}\right)-\frac{\beta u^{\prime}\left(x^{u a}\right) y}{1-\beta u^{\prime}\left(x^{u a}\right)} \geq 0,
$$

and (44) holds. 


\subsection{Monetary Policy}

First, consider an increase in the interest rate on reserves, with the central bank's balance sheet held fixed. In Figure 6, the $I C$ curve depicts equation (68), and the $M P$ curve depicts (62). Then, a decrease in $z^{m}$ (an increase in the nominal interest rate on reserves) shifts the $M P$ curve up from $M P_{1}$ to $M P_{2}$. As a result, $x_{1}^{r}$ decreases and $x^{r a}$ increases. But, because $k$ is held constant, from (68), $x^{u a}$ and $x^{u b}=x^{u a}$ remain unchanged. In this equilibrium, the market for government debt and private assets is essentially segmented from the market for central bank liabilities, which are held only by retail banks. An increase in the interest rate on reserves results only in a substitution from currency to reserves. From (44), currency falls, in real terms, which implies, from (67), that reserves increase. Thus, fewer transactions are conducted using currency in the $D M$, and there are more transactions using retail bank deposits backed by reserves. But the unconventional banking sector is completely insulated from this change in monetary policy, and the welfare of unconventional bank depositors is unaffected.

From (61), $z^{b}$ falls because of an increase in inflation, which increases the inflation premium on government bonds. From (65) and (66), the real rate of return on reserves rises (retails banks' collateral constraints are relaxed), while the real rate of return on private assets and government bonds is unchanged.

Second, suppose that the central bank's balance sheet is reduced in size, so $k$ declines. In Figure 7, the $I C$ curve shifts left from $I C_{1}$ to $I C_{2}$, so $x^{r c}$ and $x^{r a}$ decrease. Then, from (68), $x^{u a}$ and $x^{u b}=x^{u a}$ both increase. For this policy experiment, the retail banking sector contracts, the unconventional banking sector expands, retail bank depositors are worse off, and unconventional bank depositors are better off. From (61), $z^{b}$ falls, for two reasons. First, from (66), the real rate of return on government debt rises. Second, because $x^{r c}$ falls the inflation rate also rises, so there is a higher inflation premium on government debt. Note the the real rate of return on reserves falls, from (65). Retail banks have less collateral, which increases the liquidity premium on reserves, while unconventional banks have more collateral, which reduces the liquidity premium on government debt and private assets.

\section{Very Scarce Government Bonds, Scarce Pri- vate Assets; Inactive Interbank Market}

This equilibrium is similar to the one considered in the previous section, except that government bonds do not back the deposits of unconventional banks, but are used only in exchange by unconventional bank depositors who meet type $b$ sellers in the $D M$. In this equilibrium, unconventional banks must be indifferent between borrowing and lending on the interbank market, so

$$
z^{f}=\frac{u^{\prime}\left(x^{u a}\right)}{u^{\prime}\left(x^{r c}\right)} .
$$


Government bonds are held only to satisfy the withdrawal demand of depositors in unconventional banks, so

$$
z^{b}=\frac{u^{\prime}\left(x^{u b}\right)}{u^{\prime}\left(x^{r c}\right)},
$$

and reserves are willingly held by retail banks, so

$$
z^{m}=\frac{(1-\delta) u^{\prime}\left(x^{r a}\right)+\delta}{u^{\prime}\left(x^{r c}\right)} .
$$

Further, for the interbank market to be inactive, (63) and (64) hold. Then, (63) and (21) imply that

$$
z^{b} \geq z^{f} \geq z^{m},
$$

so that the nominal interest rate on government debt is less than the nominal interest rate on the interbank market, which is less than the interest rate on reserves. The gross real rates of return on government debt, private assets, and reserves are, respectively,

$$
\begin{gathered}
r^{b}=\frac{1}{\beta u^{\prime}\left(x^{u b}\right)}, \\
r^{l}=\frac{1}{\beta u^{\prime}\left(x^{u a}\right)}, \\
r^{m}=\frac{1}{\beta\left[(1-\delta) u^{\prime}\left(x^{r a}\right)+\delta\right]} .
\end{gathered}
$$

As in the previous section, (68) must hold. But now, because government debt finances only the consumption of unconventional bank depositors who meet type $b$ sellers in the $D M,(57)$ holds. As well, in this equilibrium, private assets are held only by unconventional banks, and these assets are not direct substitutes for any of the liabilities of the consolidated government, so market clearing in the market for private assets gives

$$
(1-\alpha)(1-\pi) x^{u a} u^{\prime}\left(x^{u a}\right)-\frac{\beta u^{\prime}\left(x^{u a}\right) y}{1-\beta u^{\prime}\left(x^{u a}\right)}=0,
$$

which solves for $x^{u a}$.

Then, we can determine an equilibrium, with $\left(x^{r c}, x^{r a}\right)$ solving (68) and (72), with $x^{u a}$ solving (73), and with $x^{u b}$ solving (57), given $z^{m}$ and $k$.

\subsection{Monetary Policy}

In this equilibrium, monetary policy works very similarly to the previous case. Indeed, we can construct Figures 6 and 7 in exactly the same way, with exactly the same effects from, respectively, an increase in the nominal interest rate on reserves, and a reduction in the central bank's balance sheet. The only difference will be in the effects of a balance sheet reduction on unconventional banks. Just as in the previous section, a reduction in $k$ causes $x^{r c}$ and $x^{r a}$ to fall. Here, given (57), $x^{u b}$ will rise, but, from (73), $x^{u a}$ stays unchanged, as the market in private 
assets is effectively segmented. As in the previous section, the balance sheet reduction will increase the nominal interest rate on government debt, increase the real interest rate on government debt, and reduce the real interest rate on reserves. But the real rate of return on private assets stays fixed.

\section{Active Interbank Market; Plentiful Govern- ment Bonds}

For current monetary policy issues in the United States, this equilibrium and the one in the following section are probably most relevant. In this case, the quantity of reserves is large enough that there will be an active interbank market, with unconventional banks lending to retail banks. However, because retail banks face a capital requirement, banks will not be able to arbitrage interest rate differentials. In particular, the interest rate on reserves will be higher in equilibrium than the interbank loan rate.

Note that in this equilibrium retail banks hold a portfolio consisting only of reserves. As mentioned in an earlier subsection, this might seem troubling for some readers, as the commercial banking sector in the U.S., while currently flush with reserves, is also intermediating other assets. In principle, we could complicate the model by including types of lending in which retail banks and unconventional banks specialize. But this should not change the flavor of our results. The key features of this equilibrium are that the retail and unconventional banking sectors are intermediating different assets, and the flow of interbank lending is just a means for unconventional banks to hold reserves indirectly.

First, given (16) and (33), the price of reserves is

$$
z^{m}=\frac{(1-\delta) u^{\prime}\left(x^{r a}\right)+\delta}{u^{\prime}\left(x^{r c}\right)} .
$$

Next, because retail banks are borrowers in the interbank market, (13) must hold, so given (33),

$$
z^{f}=\frac{u^{\prime}\left(x^{r a}\right)}{u^{\prime}\left(x^{r c}\right)},
$$

and (75) and (14) imply that retail banks strictly prefer not to lend on the interbank market. Because unconventional banks are lenders on the interbank market, (22) holds, so given (33), (19), and (20), we get

$$
z^{f}=z^{b}=\frac{u^{\prime}\left(x^{u a}\right)}{u^{\prime}\left(x^{r c}\right)}=\frac{u^{\prime}\left(x^{u b}\right)}{u^{\prime}\left(x^{r c}\right)} .
$$

Therefore, as long as $u^{\prime}\left(x^{r a}\right)>1$, so that there is inefficiency in exchange when retail bank depositors trade with type $a$ sellers, from (74) and (75), $z_{m}<z^{f}=$ $z^{b}$. That is, the nominal interest rate on reserves exceeds the interbank interest rate and the interest rate on government debt, just as we currently observe in U.S. financial markets. 
The gross real rate of return on reserves is

$$
r^{m}=\frac{1}{\beta\left[(1-\delta) u^{\prime}\left(x^{r a}\right)+\delta\right]},
$$

while the gross real rates of return on government debt, interbank lending, and private assets, are all equal to

$$
r^{b}=\frac{1}{\beta u^{\prime}\left(x^{u a}\right)} .
$$

Equations (5), (9), (11), (18), (26), (33), (28)-(32), (74), (75), and (76) give

$$
\begin{aligned}
& (1-\alpha \rho) x^{r a}\left[(1-\delta) u^{\prime}\left(x^{r a}\right)+\delta\right] \\
& +\alpha \rho x^{r c} u^{\prime}\left(x^{r c}\right)(1-\delta) \\
= & V(1-\delta)+\frac{\beta\left[(1-\delta) u^{\prime}\left(x^{r a}\right)+\delta\right] y}{1-\beta u^{\prime}\left(x^{r a}\right)}+\frac{\delta(V-k)}{u^{\prime}\left(x^{r a}\right)},
\end{aligned}
$$

where $k$, as above, is the size of the central bank's balance sheet. Then, we can solve for an equilibrium by solving (79) and (74) for $\left(x^{r c}, x^{r a}\right)$ given $V, z^{m}$, and $k$. Then

$$
u^{\prime}\left(x^{r a}\right)=u^{\prime}\left(x^{u a}\right)=u^{\prime}\left(x^{u b}\right)
$$

solves for $x^{u a}=x^{u b}=x^{r a}$

A necessary condition for an equilibrium to exist is that the equilibrium solution $\left(x_{1}^{r}, x^{r a}, x^{u b}, x^{u a}\right)$ satisfy

$\alpha \rho x^{r c} u^{\prime}\left(x^{r c}\right)+\frac{\alpha(1-\rho) x^{r a}\left[(1-\delta) u^{\prime}\left(x^{r a}\right)+\delta\right]}{1-\delta} \leq k \leq V-(1-\alpha) \pi x^{u a} u^{\prime}\left(x^{u a}\right)$,

which states that the size of the central bank's balance sheet $k$ needs to be greater than what is required, in terms of assets, to finance consumption by retail bank depositors, and that $k$ be small enough that there are sufficient government bonds to finance consumption by unconventional bank depositors who meet type $b$ sellers in the $D M$.

\subsection{Monetary Policy}

Analyzing the effects of an increase in the nominal interest rate on reserves is, to start with, qualitatively identical to the previous two cases. This works exactly as in Figure 6, with $x^{r c}$ decreasing and $x^{r a}$ increasing, so, from (80), $x^{u a}$ and $x^{u b}$ increase. Thus, with the size of the central bank's balance sheet fixed, an increase in the nominal interest rate on reserves leads to substitution from currency to reserves. Effectively, reserves are substitutes in this equilibrium for private assets and government debt in banks' portfolios, because of the active interbank market, so deposit liabilities expand in both retail and unconventional banks, with transactions involving currency decreasing, but transactions using all other assets increasing. 
As well, from (76), the nominal interest rates on government debt and interbank lending increase. Further, from (77) and (78), the real interest rates on all assets - reserves, government debt, interbank loans, and private assets increase. This occurs because there is a larger supply of collateralized assets, which relaxes the capital constraints of retail banks and the collateral constraints of unconventional banks, and thus reduces liquidity premia.

Given (??) and (75), the difference between the nominal interest rates on reserves and interbank loans is

$$
\frac{1}{z^{m}}-\frac{1}{z^{f}}=\frac{1}{z^{m}}\left\{\frac{\delta\left[u^{\prime}\left(x^{r a}\right)-1\right]}{u^{\prime}\left(x^{r a}\right)}\right\} .
$$

So, note in (82) that this interest rate differential depends positively on the capital requirement $\delta$, and disappears when $\delta=0$. Further, given $z^{m}$, the interest rate differential declines as the inefficiency in $D M$ exchange, measured by $u^{\prime}\left(x^{r a}\right)$, declines. Thus, when $z^{m}$ falls, in (82) there are two opposing effects on the interest rate differential. The nominal interest rate on reserves goes up, but $D M$ inefficiency declines, so the interest rate differential could rise or fall.

In Figure 8, a decrease in the size of the central bank's balance sheet, $k$, acts to shift the $I C$ curve to the right from $I C_{1}$ to $I C_{2}$, so $x^{r c}$ and $x^{r a}$ increase. Therefore, from (80), $x^{u b}$ and $x^{u a}$ increase. Since $z^{m}$ is fixed in this experiment and $x^{r a}$ increases, from (82) the margin between the interest rate on reserves and the interbank loan rate falls. Therefore, the nominal interest rate on interbank loans and government debt must rise, so $z^{f}=z^{b}$ falls.

Reducing the size of the central bank's balance sheet also serves to increase the quantity of government debt held by unconventional banks, and reduces the amount of interbank lending from unconventional banks to retail banks. Perhaps surprisingly, the real quantity of currency rises, which implies that reserves must be lower. In spite of this, retail bank deposits expand.

An important point to note is that the balance sheet reduction unambiguously increases the welfare of both retail bank depositors and unconventional bank depositors. Basically, this is because consolidated government debt is more costly for financial intermediaries to hold as reserves than as government debt, in this equilibrium.

\section{Active Interbank Market; Scarce Government Bonds}

This equilibrium is qualitatively identical to the one in the previous subsection, except that the supply of government bonds is small enough that bonds serve only to finance consumption by unconventional bank depositors who make purchases in the DM from type $b$ sellers. Here, (74) and (75) hold, but

$$
z^{b}=\frac{u^{\prime}\left(x^{u b}\right)}{u^{\prime}\left(x^{r c}\right)},
$$


and because $x^{u b} \leq x^{u a}$ in this equilibrium (due to the scarcity of government debt), from (74), (75), and (83), $z^{b} \geq z^{f}>z^{m}$. Therefore, the nominal interest rate on government debt is lower than the interbank interest rate, which is lower than the interest rate on reserves. The gross real rates of return on government bonds, interbank lending (equal to the gross rate of return on private assets), and reserves, respectively, are

$$
\begin{gathered}
r^{b}=\frac{1}{\beta u^{\prime}\left(x^{u b}\right)}, \\
r^{f}=\frac{1}{\beta u^{\prime}\left(x^{r a}\right)}, \\
r^{m}=\frac{1}{\beta\left[(1-\delta) u^{\prime}\left(x^{r a}\right)+\delta\right]} .
\end{gathered}
$$

In this equilibrium, the value of currency, government bonds, and reserves outstanding, respectively, are given by (44), (57), and (60).

Similar to the derivation of (79) in the previous section,

$$
\begin{aligned}
& {[1-\alpha \rho-(1-\alpha) \pi] x^{r a}\left[(1-\delta) u^{\prime}\left(x^{r a}\right)+\delta\right] } \\
& +\alpha \rho x^{r c} u^{\prime}\left(x^{r c}\right)(1-\delta) \\
= & k(1-\delta)+\frac{\beta\left[(1-\delta) u^{\prime}\left(x^{r a}\right)+\delta\right] y}{1-\beta u^{\prime}\left(x^{r a}\right)},
\end{aligned}
$$

and, because government debt is used in exchange only by unconventional bank depositors who purchase in the $D M$ from type $b$ sellers, we have

$$
V-k=(1-\alpha) \pi x^{u b} u^{\prime}\left(x^{u b}\right)
$$

Then, given

$$
u^{\prime}\left(x^{u a}\right)=u^{\prime}\left(x^{r a}\right),
$$

we can solve for $\left(x^{r c}, x^{r a}\right)$ as the solution to (87) and (74). Then (89) solves for $x^{u a}$, and $x^{u b}$ is determined by (88).

In equilibrium, similar to (81), the following must be satisfied in equilibrium,

$$
\alpha \rho x^{r c} u^{\prime}\left(x^{r c}\right)+\frac{\alpha(1-\rho) x^{r a}\left[(1-\delta) u^{\prime}\left(x^{r a}\right)+\delta\right]}{1-\delta} \leq k \leq V .
$$

\subsection{Monetary Policy}

First, an increase in the nominal interest rate on reserves, with $k$ fixed, works just as in Figure 6, so $x^{r c}$ decreases and $x^{r a}$ increases. Then, from (89), $x^{u a}$ increases, and (88) implies that $x^{u b}$ is unaffected. This implies, from (83), that the nominal interest rate on government debt goes up, but this is only due to the fact that inflation increased; from (84), the real interest rate on government debt is unaffected. The increase in the interest rate on reserves causes substitution between central bank liabilities - the quantity of currency 
goes down, and reserves go up in real terms, with total central bank liabilities unchanged. Thus, deposit liabilities at retail banks and unconventional banks expand, and there is an increase in interbank lending. From (85) and (86), the real rates of return on private assets, interbank lending, and reserves all increase, due to the fact that banks' collateral constraints have been relaxed and liquidity premia fall.

What happens to the margin between the nominal interest rates on reserves and government debt?. The nominal interest rate on government debt rises, as does the interest rate on reserves but, as in the previous case, (82) tells us that the difference between the nominal interest rate on reserves and the interbank rate could increase or decrease.

A decrease in the size of the central bank's balance sheet works the same as in Figure 7, in that $x^{r c}$ and $x^{r a}$ both decrease. Therefore, from (89), there is a decrease in $x^{u a}$, but $x^{u b}$ increases given (88). Thus, $z^{b}$ falls, from (83). Because $z^{m}$ is fixed for this experiment and $x^{r c}$ falls, $z^{f}$ rises. As a result, the margin between the interbank loan rate and the interest rate on government debt declines, but the margin between the interbank loan rate and the interest rate on reserves increases. From (84)-(86), the real rates of return on government debt, interbank loans (equal to the rate of return on private assets), and reserves, respectively, will increase, decrease, and decrease.

\section{Reverse Repurchase Agreements}

From the Fed's point of view, a reverse repurchase (reverse repo) agreement is a liability of the Fed, and the collateral backing this liability consists of assets in the Fed's portfolio. The key feature of this liability is that it can be held by financial institutions that cannot hold reserve accounts, or by institutions that can hold reserve accounts but cannot receive interest on reserves. Economically, it is irrelevant that this Fed liability is secured - the Fed will never default on its liabilities - so, in the model, we will interpret a reverse repo facility (an ONRRP facility) at the central bank as reserves that can be held by unconventional banks, and purchased at a price $z^{\circ}$ in terms of money. Assume that reverse repos cannot serve the same role as government debt in transactions - they can only serve as backing for the deposits of unconventional banks, and are not accepted in exchange by type $b$ borrowers. If we follow our interpretation that the transaction by an unconventional buyer with a type $b$ seller involves rehypothecation of the collateral posted by the unconventional bank to secure its liability with the buyer, then this fits reality. In practice, rehypothecation by the counterparties in reverse repo transactions with the Fed either cannot take place, or does not, depending on the counterparty.

So long as $z^{o} \geq z^{m}$, as we assume, it is optimal for retail banks to hold regular reserves rather than reverse repos. We will consider how the reverse repo facility works only in the last two cases we considered above, in which there is an active interbank market.

Let $z^{o} \bar{o}$ denote the value of reverse repos issued each period by the central 
bank, which have a redemption value in terms of goods in the next period of $\frac{\bar{o}}{\mu}$. Then, as before, let $k$ denote the value of central bank liabilities, but now central bank liabilities consist of currency, reserves held by retail banks, and reverse repos held by unconventional banks. Let $k_{1}$ denote the sum of the values of currency and reserves outstanding, and $k_{2}$ the value of reverse repurchase agreements outstanding, with $k=k_{1}+k_{2}$. If government bonds are plentiful, we can then rewrite equation (79) as

$$
\begin{aligned}
& (1-\alpha \rho) x^{r a}\left[(1-\delta) u^{\prime}\left(x^{r a}\right)+\delta\right]+\alpha \rho x^{r c} u^{\prime}\left(x^{r c}\right)(1-\delta) \\
= & V(1-\delta)+\frac{\beta\left[(1-\delta) u^{\prime}\left(x^{r a}\right)+\delta\right] y}{1-\beta u^{\prime}\left(x^{r a}\right)}+\frac{\delta\left(V-k_{1}\right)}{u^{\prime}\left(x^{r a}\right)}
\end{aligned}
$$

Otherwise, everything is identical to the case with plentiful government debt and an active interbank market, in the absence of a reverse repo facility, except that $z^{o}=z^{b}=z^{f}$ in equilibrium. That is reverse repos, government debt, and interbank loans (and private assets as well) are perfect substitutes for unconventional banks.

Then, following our previous analysis, given $V, k_{1}$, and $z^{m}$, equations (90) and (74) solve for $\left(x^{r c}, x^{r a}\right)$. Then (80) solves for $x^{u a}=x^{u b}$.

The experiment we want to consider involves holding constant the size of the central bank's balance sheet, $k$, and the nominal interest rate on reserves. Then, increase the size of the reverse repo facility $k_{2}$, which implies that $k_{1}$ falls - more reverse repos implies less currency and reserves. Assuming, as above, that $\delta$ is sufficiently small, the effects of this experiment are as in Figure 8, so that $x^{r c}$ and $x^{r a}$ increase. Then, from (80), $x^{u a}$ and $x^{u b}$ increase. This works in exactly the same manner as a central bank balance sheet reduction in the case with no reverse repo facility. The margin between the nominal interest rate on reserves and the interbank loan rate (equal to the nominal interest rate on government debt) falls. Thus, the reverse repo facility will in general tighten up the differential that exists between the interest rate on reserves and the interbank loan rate.

In this case, the reverse repo facility acts - just as the Fed appears to have intended - to put a floor under the interbank rate. Further, perhaps counterintuitively, increasing the quantity of reverse repos outstanding acts to expand financial intermediation in the unconventional banking sector and in the retail banking sector as well. One might anticipate that the change in composition of the central bank's liabilities, away from liabilities that only retail banks can hold (reserves), would reduce the activities of the retail banking sector. Assets of the retail banking sector indeed have to fall, but so does interbank lending, which is simply an indirect means for unconventional banks to hold reserves. With reverse repos, the unconventional banking sector can hold central bank liabilities at lower cost, which works to expand useful intermediation activity in both the retail and unconventional banking sectors.

Further, the reverse repo facility acts to increase welfare, for both retail and unconventional bank depositors. Again, this is due to a reduction in balance sheet costs that occurs with a shift in central bank liabilities from retail banks 
to unconventional banks.

In the case in which government bonds are scarce, we can solve for $\left(x^{r c}, x^{r a}\right)$ from $(74)$ and

$[1-\alpha \rho-(1-\alpha) \pi] x^{r a}\left[(1-\delta) u^{\prime}\left(x^{r a}\right)+\delta\right]+\alpha \rho x^{r c} u^{\prime}\left(x^{r c}\right)(1-\delta)=k(1-\delta)+\frac{\delta k_{2}}{u^{\prime}\left(x^{u a}\right)}$.

Then (88) and (89) solve for $x^{u b}$ and $x^{u a}$, respectively. Therefore, if we fix $k$ and $z^{m}$, and increase $k_{2}$, assuming that $\delta$ is small, then, $x^{r c}, x^{r a}$, and $x^{u a}$ increase, but $x^{u b}$ remains unchanged. Then, from (83), $z^{b}$ rises and, from (82), $z^{f}$ falls. So, with the nominal interest rate on reserves fixed, the reverse repo program acts to increase the nominal interest rate on interbank loans, but the nominal interest rate on government debt falls, due to a drop in the inflation premium. The real rate of return on government debt remains unchanged, while real rates of return on all other assets rise.

As in the previous case, the reduction in balance sheet costs that occurs with a shift in central bank liabilities between the two banking sectors acts to expand both sectors, and to increase the welfare of retail and unconventional bank depositors.

\section{Conclusion}

A two-sector model of financial intermediation was constructed in this paper to examine issues related to the central bank's balance sheet size, payment of interest on reserves, and the functioning of the floor system (with a sub-floor) currently in place in the United States. In the model, changes in the size of the central bank's balance sheet and changes in the interest rate on reserves can have similar effects on nominal interest rates, but very different effects on quantities and economic welfare. Increases in the central bank's balance sheet can reduce welfare because of the balance sheet costs of reserve-holding in the retail banking sector. An ON-RRP facility at the central bank acts to increase welfare through a reduction in balance sheet costs, and also puts a floor under the interbank interest rate. However, an increase in the quantity of reverse repos, holding constant the central bank's balance sheet size, can increase the margin between the interbank interest rate and the interest rate on government debt.

How could this model be extended? The analysis here dealt only with stationary equilibria, but extending the model to permit aggregate risk and policy dynamics should be feasible. As well, we could consider the implications of alternative central bank liabilities, for example circulating interest-bearing short-term securities, or "Fed bills." Such securities can be issued by the Swiss National Bank, for example. Finally, an important issue concerns the effects of paying negative interest on reserve balances. To consider this issue, we would need to add some frictions associated with currency (principally theft), so as to permit the zero lower bound on the nominal interest rate to be relaxed. 


\section{References}

Afonso, G., Entz, A., and LeSueur, E. 2013a. "Who's Lending in the Fed Funds Market?" Liberty Street Economics, Federal Reserve Bank of New York.

Afonso, G., Entz, A., and LeSueur, E. 2013b. "Who's Borrowing in the Fed Funds Market?" Liberty Street Economics, Federal Reserve Bank of New York.

Afonso, G., and Lagos, R. 2015. "Trade Dynamics in the Market for Federal Funds," Econometrica 83, 263-313.

Andolfatto, D., and Williamson, S. 2015. "Scarcity of Safe Assets, Inflation, and the Policy Trap," Journal of Monetary Economics 73, 70-92.

Armenter, R. and Lester, B. 2015. "Excess Reserve and Monetary Policy Normalization," working paper, Federal Reserve Bank of Philadelphia.

Berentsen, A. and Monnet, C. 2008. "Monetary Policy in a Channel System," Journal of Monetary Economics 55, 1067-1080.

Bernanke, B. 2012. "Monetary Policy Since the Onset of the Crisis," Board of Governors of the Federal Reserve System.

Bianchi, J., and Bigio, S. 2014. "Banks, Liquidity Management and Monetary Policy," NBER Working Paper No. 20490.

Board of Governors, 2014. "Policy Normalization Principles and Plans," http://www.federalreserve.gov/newsevents/press/monetary/20140917c.htm

Carpenter, S., Ihrig, J., Klee, E., Boote, A., and Quinn, D. 2013. "The Federal Reserve's Balance Sheet: A Primer and Projections," Finance and Economics Discussion Series 2013-01. Board of Governors of the Federal Reserve System.

Goodfriend, M. 2002. "Interest on Reserves and Monetary Policy," Federal Reserve Bank of New York Policy Review.

Lagos, R. and Wright, R. 2005. "A Unified Framework for Monetary Theory and Policy Analysis." Journal of Political Economy 113, 463-484.

Martin, A., McAndrews, J., Palida, A., and Skeie, D. 2013. "Federal Reserve Tools for Managing Rates and Reserves," staff report \#642, Federal Reserve Bank of New York.

Williamson, S. 2012. "Liquidity, Monetary Policy, and the Financial Crisis: A New Monetarist Approach," American Economic Review 102, 2570-2605.

Williamson, S. 2015a. "Scarce Collateral, the Term Premium, and Quantitative Easing," forthcoming, Journal of Economic Theory. 
Williamson, S. 2015b. "Central Bank Purchases of Private Assets," working paper, Federal Reserve Bank of St. Louis. 


\section{Figure 1}

\section{Percent}

CA Dollars (Mil.)

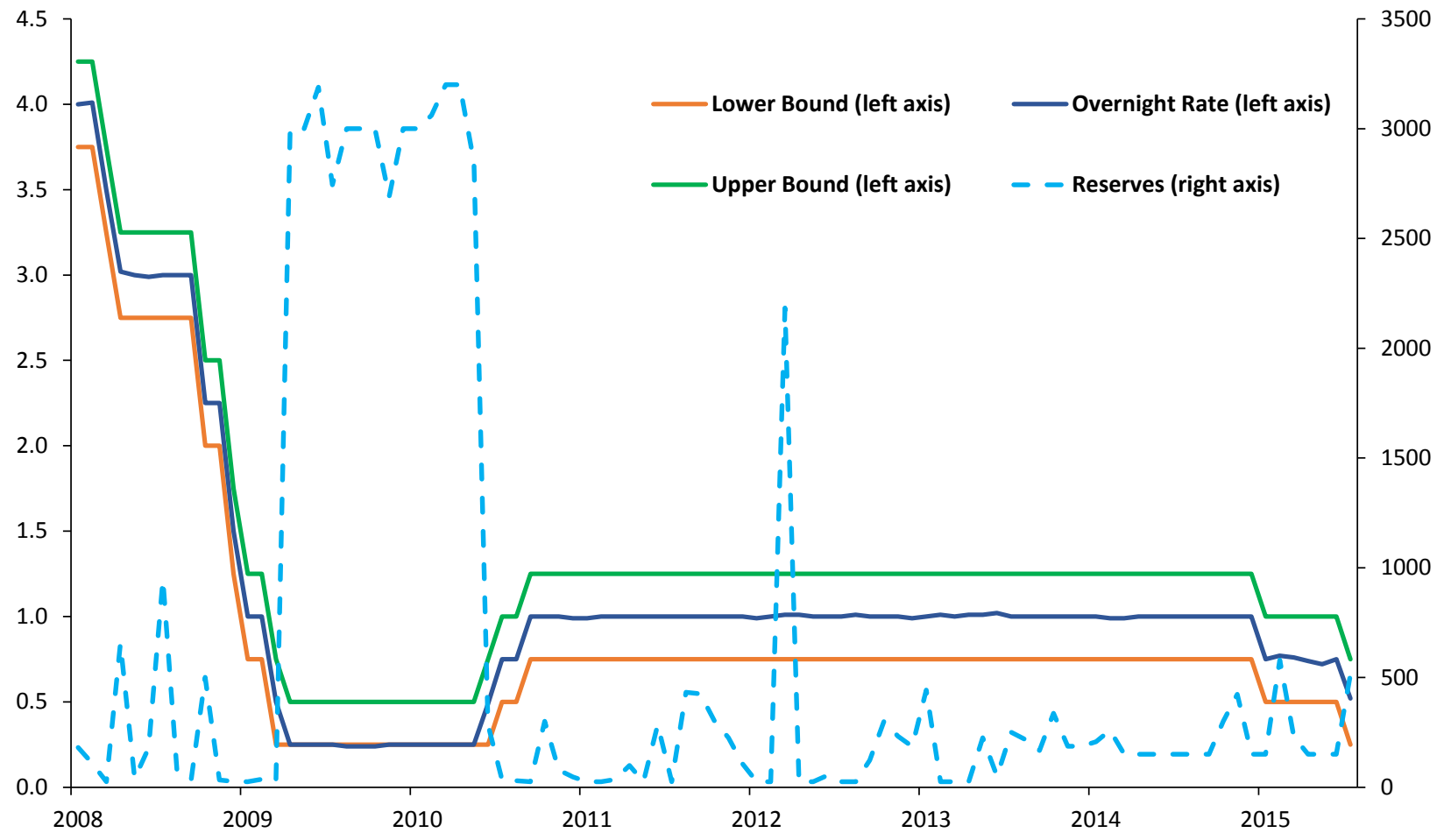

Sources: Bank of Canada/Haver Analytics 
Figure 2

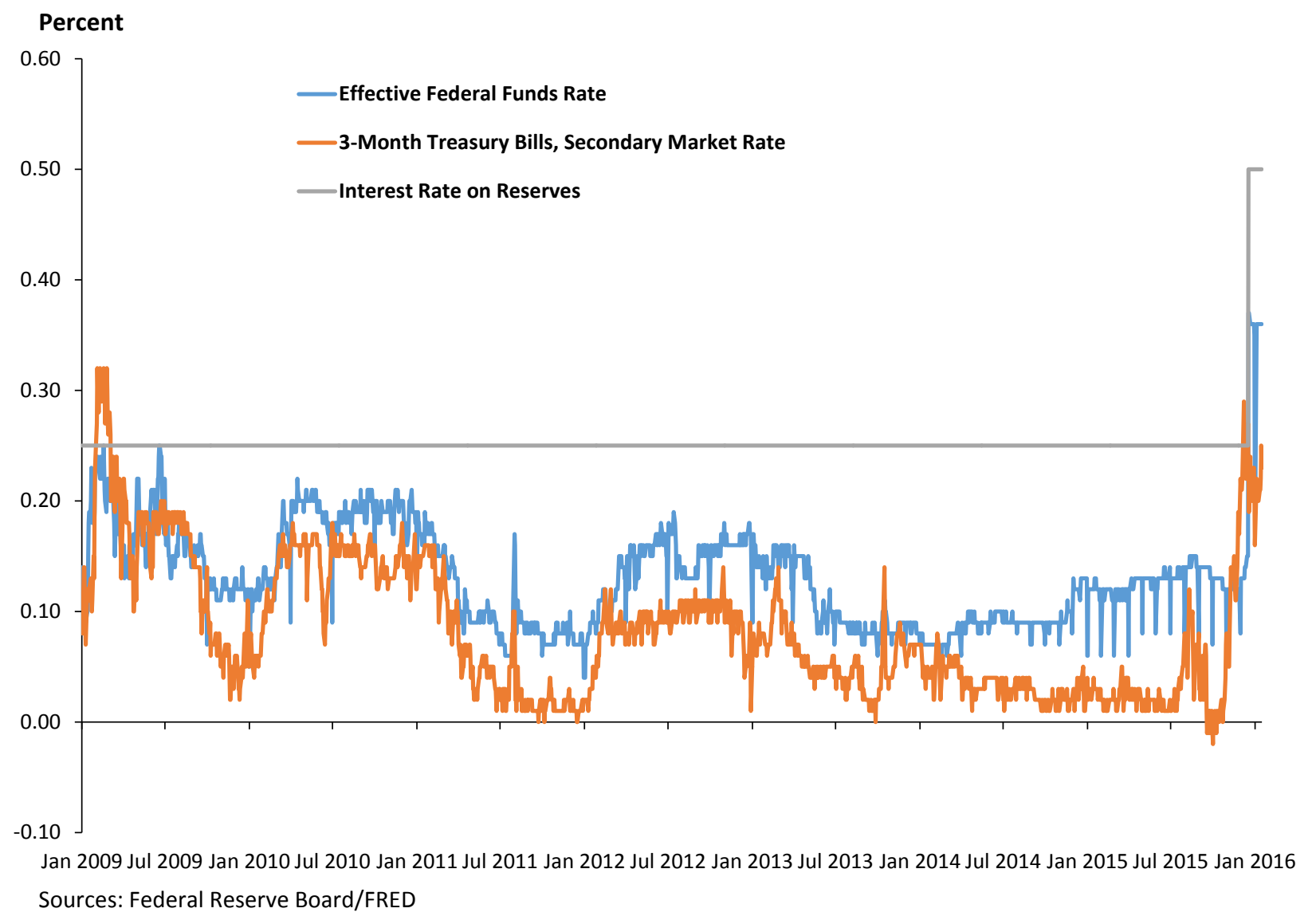


Figure 3

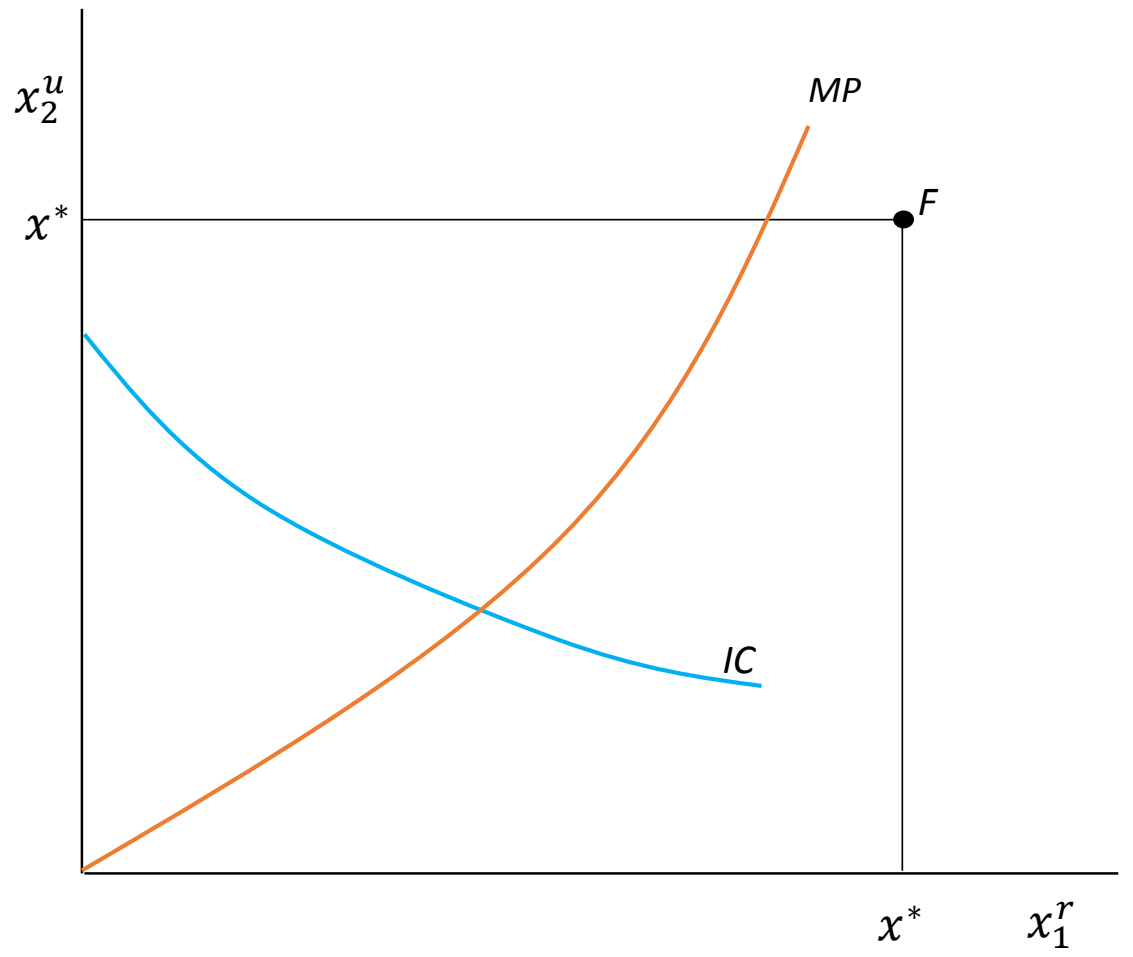

Figure 4

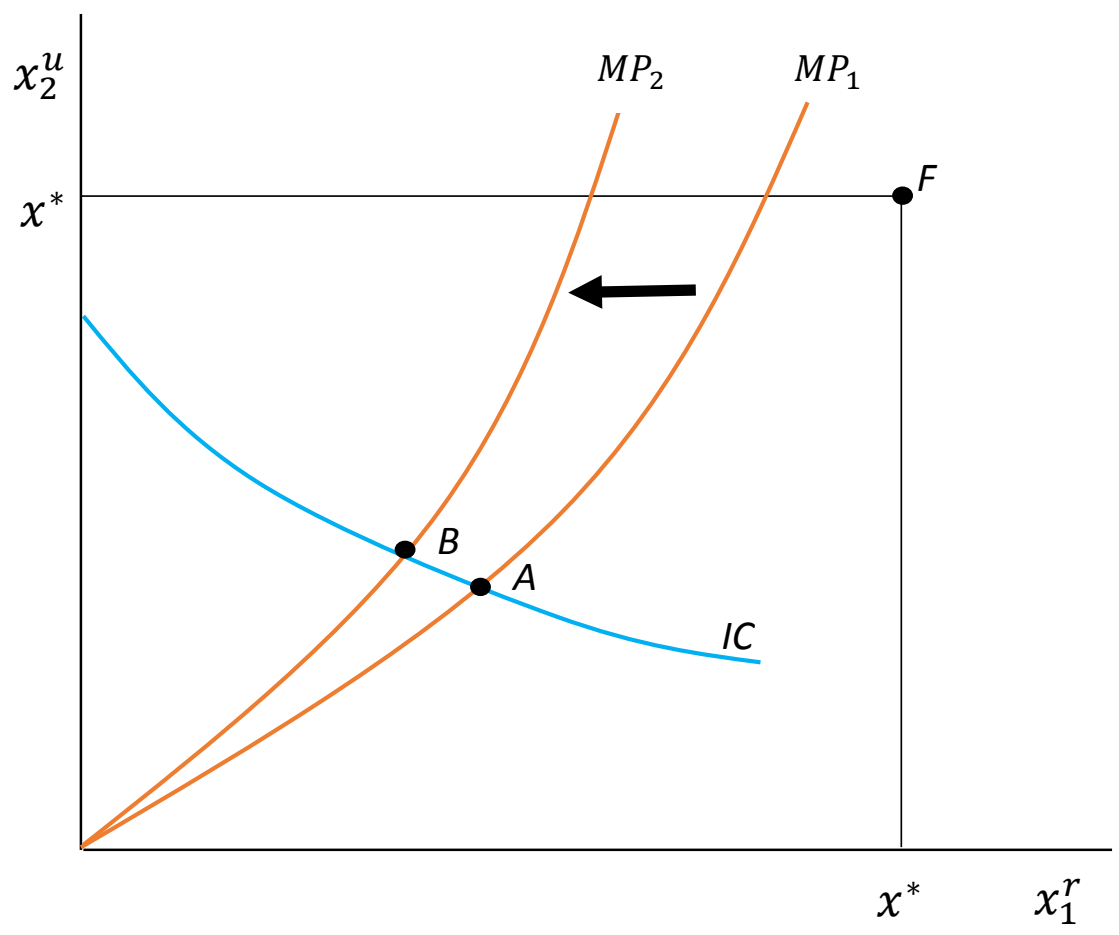


Figure 5

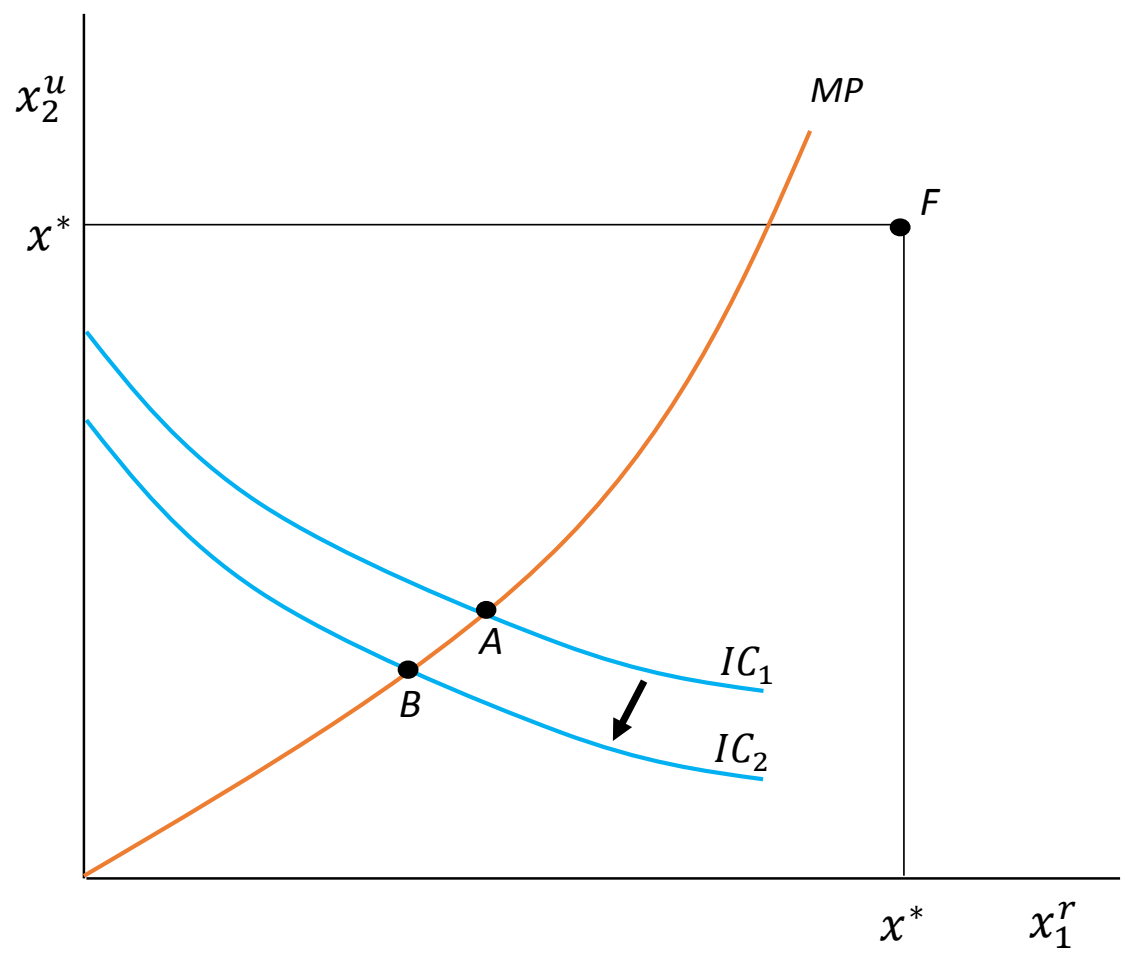

Figure 6

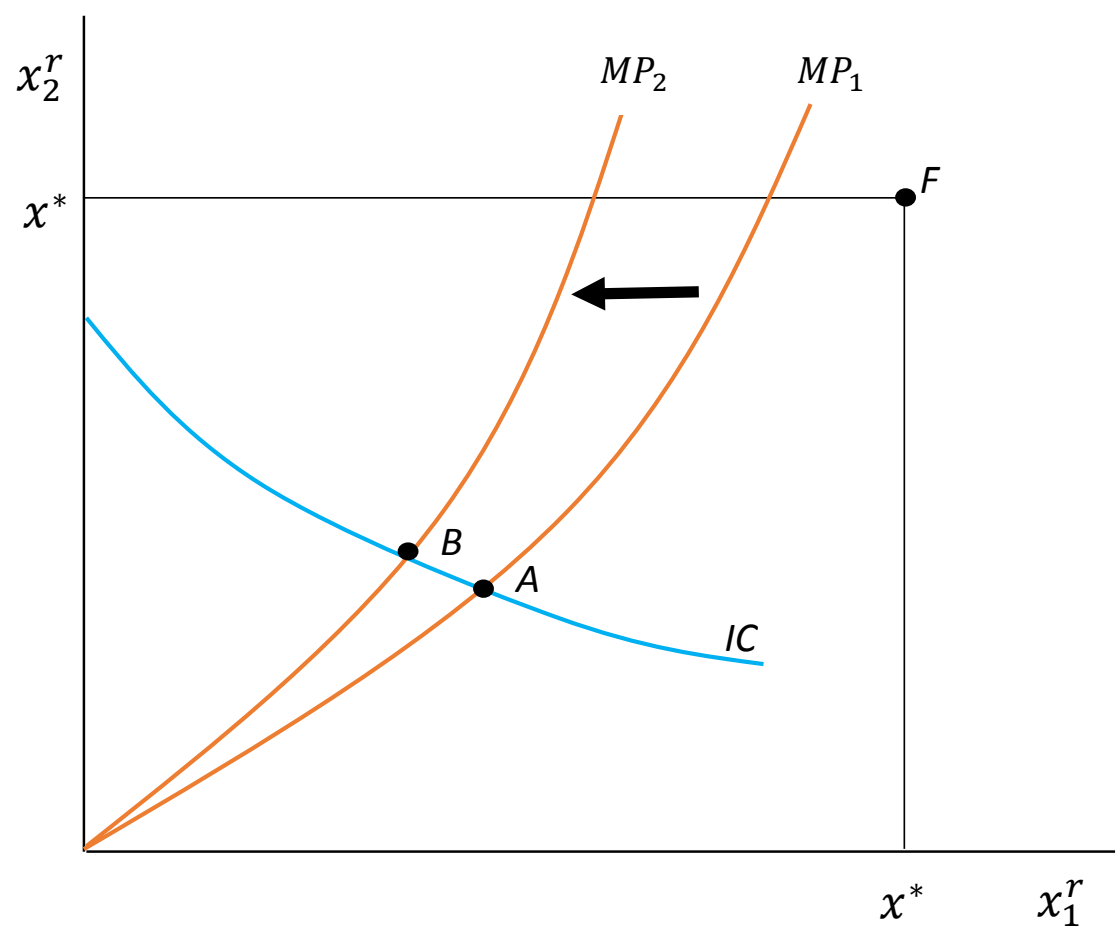


Figure 7

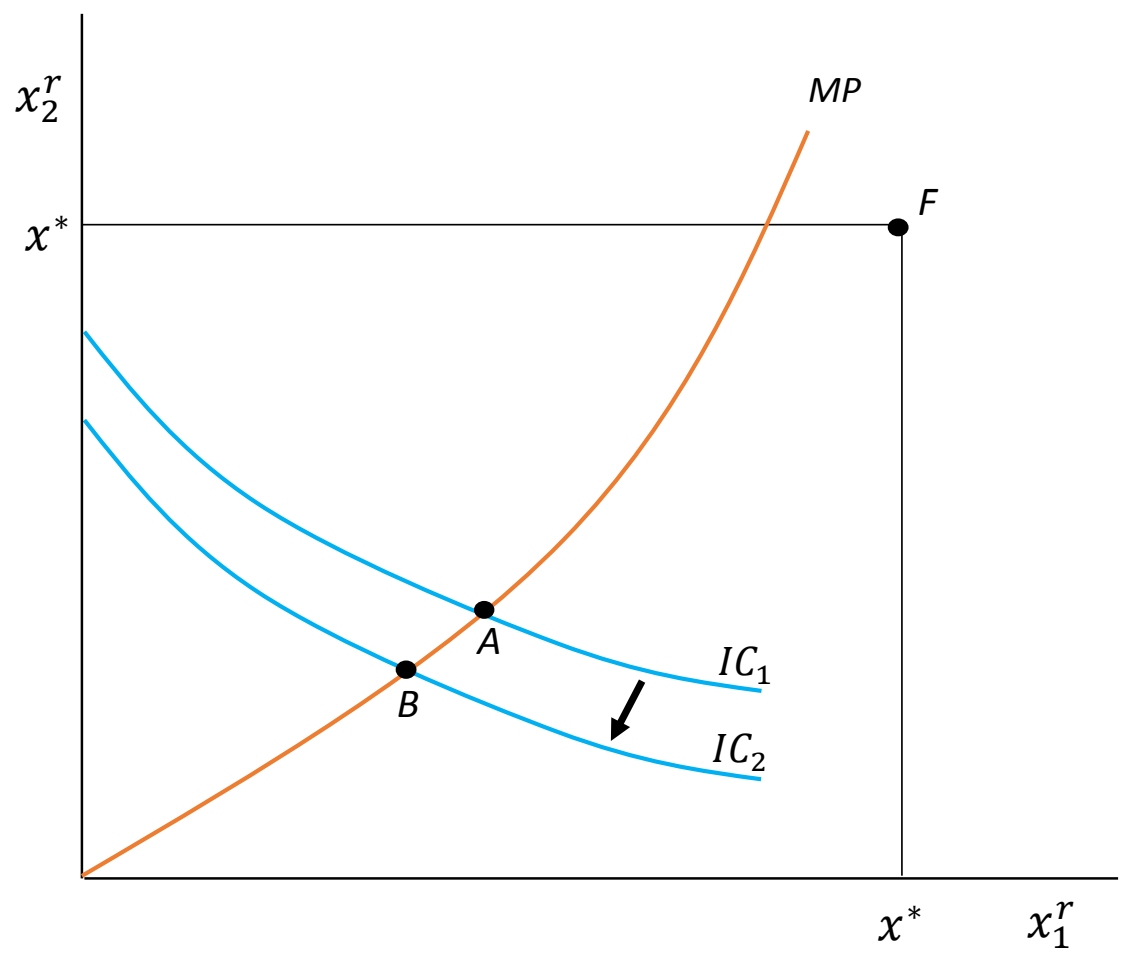

Figure 8

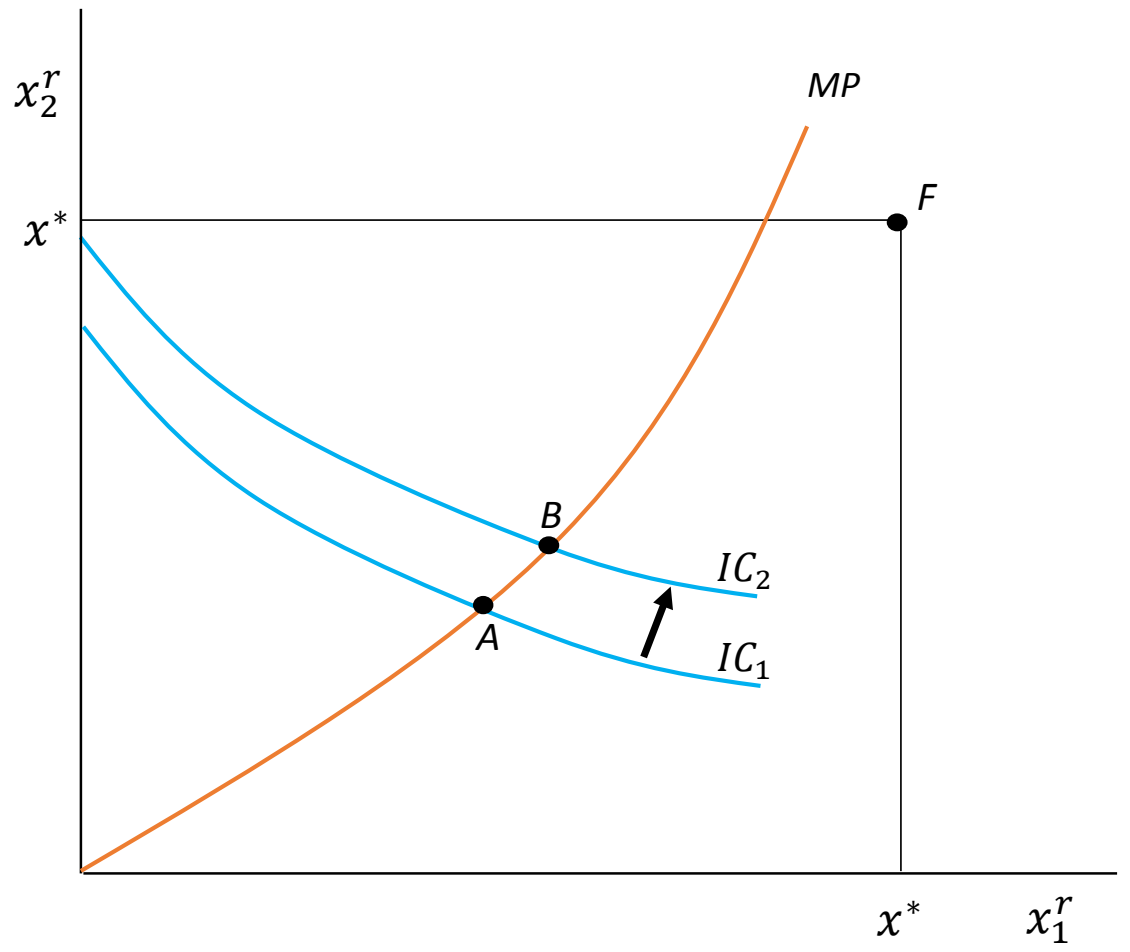

